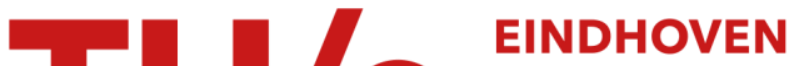 UNIVERSITY OF TECHNOLOGY
}

\section{Academic communication and Internet Discussion Groups : transfer of information or creation of social contacts?}

\section{Citation for published version (APA):}

Matzat, U. (2004). Academic communication and Internet Discussion Groups : transfer of information or creation of social contacts? Social Networks, 26(3), 221-255. https://doi.org/10.1016/j.socnet.2004.04.001

DOI:

10.1016/j.socnet.2004.04.001

Document status and date:

Published: 01/01/2004

\section{Document Version:}

Publisher's PDF, also known as Version of Record (includes final page, issue and volume numbers)

\section{Please check the document version of this publication:}

- A submitted manuscript is the version of the article upon submission and before peer-review. There can be important differences between the submitted version and the official published version of record. People interested in the research are advised to contact the author for the final version of the publication, or visit the $\mathrm{DOI}$ to the publisher's website.

- The final author version and the galley proof are versions of the publication after peer review.

- The final published version features the final layout of the paper including the volume, issue and page numbers.

Link to publication

\section{General rights}

Copyright and moral rights for the publications made accessible in the public portal are retained by the authors and/or other copyright owners and it is a condition of accessing publications that users recognise and abide by the legal requirements associated with these rights.

- Users may download and print one copy of any publication from the public portal for the purpose of private study or research.

- You may not further distribute the material or use it for any profit-making activity or commercial gain

- You may freely distribute the URL identifying the publication in the public portal.

If the publication is distributed under the terms of Article 25fa of the Dutch Copyright Act, indicated by the "Taverne" license above, please follow below link for the End User Agreement:

www.tue.nl/taverne

Take down policy

If you believe that this document breaches copyright please contact us at:

openaccess@tue.nl

providing details and we will investigate your claim. 


\title{
Academic communication and Internet Discussion Groups: transfer of information or creation of social contacts?
}

\author{
Uwe Matzat* \\ Department of Technology Management, Eindhoven University of Technology, \\ PO Box 513, 5600 MB Eindhoven, The Netherlands
}

\begin{abstract}
This paper analyzes the role of Internet Discussion Groups (IDGs) in informal academic communication. It examines the claims in the literature that there are general benefits of academic mailing lists and newsgroups for researchers. Different hypotheses relating to potential contact and information benefits are tested with data of a random sample of English and Dutch university researchers within the humanities, the social and natural sciences. The outcomes support hypotheses about a few information effects and, more often, contact benefits of IDGs. Researchers build up weak contacts that make their research more visible and that make them more aware of other researchers' work. These weak contacts are useful for the reception of new research papers. As a result, IDGs provide access to social capital. However, contrary to what is stated in the literature, the data shows no evidence for expectations about equalizing effects on the general structure of academic communication. IDGs do not reduce inequalities in the opportunities to use informal communication channels.
\end{abstract}

(C) 2004 Elsevier B.V. All rights reserved.

Keywords: Academic communication; Internet discussion group; Social capital

\section{Introduction}

There is much speculation about the potential of information technologies. According to predictions the "information superhighway" will transform the world into a global village. The communication revolution will lead to "[t]he death of distance" (Cairncross, 1997). In

\footnotetext{
The research project was conducted while the author was a Ph.D. student at the Interuniversity Center for Social Science Theory and Methodology (ICS), Department of Sociology, University of Groningen (The Netherlands).

* Tel: +31 402478392 .

E-mail address: u.matzat@tm.tue.nl (U. Matzat).

URL: http://www.tue-tm-soc.nl/ matzat.
} 
the academic education system there is the virtual university, and in the research system the Internet is regarded by some as a "quantum transition" for communication among researchers (Pascha, 1995). What is certain is that the growth of the Internet has been accompanied by an explosion of predictions of the coming technological utopia, within academic circles as well as in the general public (Kling and Iacono, 1995).

A lively discussion among researchers about the potential of the new communication tools which the Internet offers is understandable. Formal and informal communication are crucial to the research community (Garvey, 1979; Meadows, 1974). New possibilities for their promotion are thus very important. The potential of the World Wide Web for online publishing is influencing the formal publication system (Peek and Newby, 1996). Academic mailing lists and newsgroups have been adopted as tools for informal communication between researchers.

Despite the large number of predictions there is a clear lack of general data to help judge the validity of these expectations (Weil, 1998; Kling, 1996). What is missing, is data that shows how a variety of different researchers, and not just some specialized user groups, use information technology (Walsh and Bayma, 1996a). This should help to evaluate whether and how researchers in general profit from the communication tool used.

This is especially true for academic Internet Discussion Groups (IDGs), as I call newsgroups and mailing lists here. We know from some single-case studies (see below) that IDGs are regarded as useful by specific groups of researchers. However, it is unclear which groups of researchers can achieve what kind of objectives with IDGs in general. The answer to this question is important for several reasons.

First, the number of academic IDGs had increased to cover almost every discipline by the middle of the 1990s (Kovacs, 1996; Mailbase, 1999a). In some countries, computing services were founded to promote and support the initiation and use of academic mailing lists. These services receive official funds from science foundations (e.g. Mailbase, 1999; H-Net, 1999). Much time, money, and effort is continuously invested in IDGs with distinct target groups - not to mention the time individual researchers spend on the maintenance of IDGs as moderators or as readers/contributors. ${ }^{1}$ The use of IDGs is no longer restricted to a minority of technically interested academics. Many researchers use them, and many lists have experienced a growing number of users during the 1990s (Mailbase, 1999b). A careful analysis can show what benefits IDGs really have for the research community, and which expectations are unwarranted. Such an analysis serves as a basis for judging whether increased expenditure on mental and financial resources for the maintenance of IDGs is justified. It prevents the expenditure of resources for certain ends that may not be attainable via these means.

Second, the success and failure of communication technologies depends crucially on the social context in which they are used. Unfortunately, little is known about which conditions are favorable for the successful adoption of a communication technology. Rather, different tools and pathways of communication exist in the different disciplines within the research

\footnotetext{
${ }^{1}$ Conner (1992) mentions that he spends on average approximately 10 hours per week on the active moderation of an IDG within the humanities. Other listowners or moderators also complain about the time requirements (Berge and Collins, 1993). Moreover, active mailing lists aggravate the problem of information overload for every user (McCarty, 1992; Whittaker and Sidner, 1997).
} 
community, and tools successful within one field are adopted in other research fields under different conditions (Kling and McKim, 2000). The costs of such diffusion by trial-and-error could be avoided if we knew more about the interplay between a communication tool and the communication conditions of a discipline. Thus, what is necessary is a better understanding of the actual use and impact of different communication technologies under different conditions (Walsh and Bayma, 1996a). A hypothesis testing, empirical analysis of the use of IDGs by researchers in a variety of different disciplines can offer some insight into the general effects of IDG use by researchers in different disciplines with distinct communication habits and needs. This makes it possible to compare the same computer-mediated communication tool under different conditions. The analysis of IDGs accordingly offers general insight into the question of which communication needs are fulfilled under what condition. This insight could help to predict some effects of other computer-mediated communication tools.

Moreover, in the social sciences, the study of social capital is regarded as an important research field of theoretical and practical interest (Portes, 1998). Social capital is a resource for individuals that is embedded in social networks, and that facilitates the attainment of the individual's aims. In the recent past, it has been proposed that the Internet should be studied to find out to what extent and under which conditions it is a source of social capital (Lin, 1999). This study analyzes to what extent IDGs are a source of social capital for university researchers.

Finally, there is a clear analytical advantage in concentrating on IDGs. Studies of the effects of computer-mediated communication (CMC) on academic communication cannot easily distinguish between cause and effect, unless panel data is used. By taking the degree of communication within an IDG as an indicator of the opportunities IDGs offer, however, this analysis makes possible only one interpretation of the causal direction between IDG use and certain benefits (see section 3 for details). The degree of communication within the IDGs used by a researcher depends on hundreds of other researchers and is not determined by the individual respondent alone. This overcomes the problem of the direction of causality which other studies have (see e.g. Walsh, 1998).

With this paper I intend to answer the question of whether the potential that IDGs are presumed to have is indeed realized to some degree at the end of the 20 th century. I focus on some outcomes of IDGs regarding the general structure of academic communication. The second section reviews hypotheses of the potential benefits which different groups of researchers could obtain by using IDGs. Moreover, special attention is given to consequences for the macro level of the informal communication network of a research field. The existing but sparse empirical evidence for these hypotheses is mentioned. I describe the drawbacks of the existing empirical studies and present the hypotheses that are tested in this study. The third section describes the data and the fourth section shows the results of the tests of the hypotheses. The fifth section summarizes the findings and discusses open questions for future research.

\section{Potential benefits of academic Internet Discussion Groups}

As early as the 1970s, the first predictions appeared of the opportunities which so-called electronic conference systems would offer to academic communication (Hiltz and Turoff, 
1978). This section will show that, although similar optimism regarding the potential of IDGs can be found in the 1990s among some academics (Gresham, 1994; Turoff and Hiltz, 1998), some skeptical voices have also been raised expressing doubts about the general relevance of some IDGs (Bainbridge, 1995).

At first glance it is surprising to find both optimistic and skeptical evaluations of IDG use more than 20 years after its inception (e.g. compare Bainbridge, 1995; Gresham, 1994; Turoff and Hiltz, 1998). The question whether and how IDGs can serve the objectives of academic research is discussed not only among observers, but also among IDG users, who have various views of how IDGs should work (Conner, 1992; McCarty, 1992). The range of different views makes it more difficult to judge the relevance of IDGs.

However, although there might be different specific consequences for different researchers, not all of them are of importance for the general population of academic users. I would like to focus on the claims made by many IDG proponents of universal, beneficial effects of IDGs on academic communication. To simplify the discussion, I make a distinction between two different general groups of potential benefits which are relevant for the large majority of researchers. I categorize them as being either an information benefit or a contact benefit.

\subsection{Information production, information transmission or just information overload?}

Hiltz and Turoff (1978) brought up many different potential benefits that IDGs can have for either individual researchers or for a whole research field. ${ }^{2}$ According to them IDGs could generate new research ideas or proposals for research among academics, from which every passive and active user of an IDG could profit. Moreover, computer conferences could allow the informal exchange of research results or of other helpful information between researchers. The authors compare such an exchange with informal discussions on the fringe of conferences. A provision of help during an informal discussion depends on the motivation of the individual researcher who does not usually get anything in return. The information transfer and provision of help within an IDG, however, take place in front of an audience and are usually recorded. Accordingly, an increase in motivation to provide help is expected.

Some of the most important intellectual benefits are those that affect the whole research community, which might profit from the enhanced opportunities for discussions. Electronic conferences could help to solve or develop theoretical, methodological and ethical controversies in a research field. This, in turn, might speed up the development of whole research fields (ibid., 210-239).

Many empirical studies of IDGs and electronic conferences have been inspired by the ideas of Hiltz, Turoff and their colleagues. Most of them consist of case studies of single or a few selective IDGs or electronic conferences. The users were usually asked to enumerate the advantages or disadvantages of IDG use, or to describe benefits they obtained or problems they experienced through IDG use (see Tombaugh, 1984; Harasim and Winkelmans, 1990; Rojo and Ragsdale, 1997a, 1997b). Other empirical evidence is rather anecdotal and consists

\footnotetext{
2 The authors themselves analyse "computerized conferencing" and not Mailing Lists or Newsgroups. However, their ideas can be found in many analyses of IDGs (e.g. Gresham, 1994; Lewenstein, 1995; McCarty, 1992). Turoff and Hiltz (1998) include in their later statements Newsgroups explicitly.
} 
of descriptions by moderators of what happened in 'their' IDGs (Conner, 1992; McCarty, 1992; Berge and Collins, 1993).

These studies show that users evaluate positively the opportunities offered by IDGs for the creation of new ideas and for the provision of research information and other helpful advice. On the other hand, many users complained about the low quality or low extent of discussion within discussion groups. These complaints have been made by users or moderators of a variety of IDGs (Conner, 1992; McCarty, 1992; Rooy, 1996). Some studies mention explicitly that IDGs are not well suited for the discussion or solution of intellectual controversies among researchers (Hiltz, 1984; Harasim and Winkelmans, 1990; Lewenstein, 1995; Tombaugh, 1984).

I conclude from these findings that the transmission of already existing knowledge is much more common in IDGs than the production of new knowledge. If IDGs have a general information potential for academic communication, this potential is grounded most of all in the possibilities for transfer of information, and not in the potential for solving controversies through discussion. However, even the claim that IDGs are a valuable tool for researchers to gain access to information and the knowledge of their colleagues rests on a shaky ground. ${ }^{3}$

The empirical evidence for these claims is derived from studies with many limitations. ${ }^{4}$ The evidence often consists of subjective descriptions of users' experiences within single deliberately selected IDGs which can be very atypical among the general population of IDGs used by researchers (e.g. Tombaugh, 1984; Harasim and Winkelmans, 1990). Only Rojo and Ragsdale (1997a,b) studied a larger number of IDGs. Furthermore, there are no systematic comparisons of users with non-users of IDGs. It is therefore completely unclear whether the use of IDGs really leads to benefits that could not be obtained more easily in a different way. To my knowledge, there are only two such comparative studies. Scholl et al. (1996) used data of a random sample of German university researchers within the social sciences. They compared researchers who are intensive users of E-Mail and IDGs with those who do not use IDGs and who use E-Mail less often. Both groups had to assess to what extent their use of computer-mediated communication (CMC) improved their ability to gather information and how effective it was in stimulating new ideas for research. The intensive users assessed these two benefits significantly more positively than the less intensive users (Scholl et al., 1996, 1997). However, the data did not allow a distinction to be made between the effects of IDG use and the effects of general E-Mail use. Cohen (1996) analyzed the use of CMC tools in a random sample of full-time faculty in chemistry, philosophy, sociology and political science in US institutions that are members of the Association of Jesuit Colleges and Universities. He found in a bivariate analysis that the more intensively the faculty used IDGs, the more positively they assessed "... how electronic mail and network access have benefited .. scholarly activities ..." with regard to "more timely access to information" and "access to new kinds of information for .. research" (ibid., 56).

\footnotetext{
${ }^{3}$ I omit one negative effect of IDGs, namely, that they aggravate the problem of information overload. This is an obvious effect of IDGs with a high number of sent messages (McCarty, 1992).

${ }^{4}$ In the following discussion, I concentrate on the evidence for benefits relating to the transfer of information. I do not consider the evidence for the creation of new ideas with the help of IDGs. The same limitations of the empirical studies apply to both kinds of evidence. I show in section four how it is possible to overcome the drawbacks in studying whether or not IDGs provide information advantages. I doubt that this is possible with regard to the analysis of the creation of new ideas.
} 
In addition, there were no effective controls for spuriousness of the effects found and their claimed relevance. Intensive users of E-Mail and IDGs will differ from non-users in many aspects. Perhaps the information benefits are due to other, uninvestigated factors and are not related to the use of IDGs and E-Mail. No study systematically controls whether information effects are IDG-induced. Nevertheless, a control for spuriousness of the associations found is crucial for evaluating the potential of IDGs.

Another disadvantage of most studies is that they describe the experienced information benefits very vaguely. Scholl et al. (1997, 355) asked their respondents whether they received "more information", whether they received "information quicker" or "easier" (ibid., 355, own translation, U.M.). Rojo and Ragsdale (1997a, p. 334) mention as benefits "keep[ing] updated", "get[ting] materials" and "get[ting] answers". However, they never asked what kind of information IDG users received. This makes it difficult to pass judgment on the specific relevance of the information that is gained from IDGs. Does the information enhance the theoretical knowledge of researchers about their research field or is it advice related to practical problems that the researchers have? I elaborate on this in the section concerning the hypotheses.

Finally, the authors always associate the information benefits with the use of the IDG (e.g. Rojo and Ragsdale, 1997a, 1997b; Scholl et al., 1996; Cohen, 1996). It was asked, for example, whether the use of an IDG led to some benefits (e.g. more information). It is never clear whether these benefits were really obtained through the use of IDGs or whether intensive users justified to themselves their time consuming use of IDGs by assuming that it led to benefits. There are no measures of the effects (benefits) that are independent to the assumed causes (IDG use).

As a consequence it is unsurprising that since the mid-1990s there are becoming more and more researchers who doubt the general relevance of IDGs to academic communication. Lewenstein (1995) analyzed how physicists used a newsgroup. He argues that observers and participants in research activities used different electronic communication tools. According to him smaller electronic spaces with more limited access than newsgroups might be more adequate for active researchers. This resembles the observation of Bainbridge (1995), who argues that public newsgroups have too high a noise rate. Many researchers would react by leaving these groups and concentrating on more restricted mailing lists.

However, the available data, lacking any systematic evaluation, does not allow a judgment of these assessments to be made.

\subsection{Transformation of invisible colleges, peripherality effects or just chat?}

Some researchers regard the discussions in IDGs to be low quality research and have stopped using them (see e.g. the descriptions in Bainbridge, 1995; Conner, 1992). One might counter that this kind of electronic conversation is important for the interactive formulation of new ideas (Conner, 1992). Conversation, however, does more than stimulate the formation of new ideas. Studies of the academic communication system demonstrate that the benefits of informal communication are only to a small extent the intended result of planned action. They are often a by-product of interactions that were initiated for other reasons. Many merits of an academic meeting or a conference are gained not through the presentation of papers but through informal conversation between individual researchers which was 
initiated outside of any formal arrangements. Such conversation can nevertheless lead to important new contacts between researchers (Menzel, 1962, 1966). The discussion within an IDG is sometimes compared to discussions on the fringe of conferences (Gresham, 1994; Hiltz and Turoff, 1978). E-Mail communication is a peculiar mixture of textual and conversational elements (McCarty, 1992; Rice, 1997), which suggests that it facilitates not only the transmission of impersonal information on research questions, but also acts as a social medium in which personal information about the researchers is exchanged. Empirical studies show that E-Mail communication makes possible the sending out of social signals relating to the sender, especially during longer-lasting communication processes (e.g. Korenman and Wyatt, 1996; Walther, 1995).

These considerations have become more important since the 1980s because science policy gives clear incentives for collaboration and co-operation between researchers (Ziman, 1994). Empirical indications of an increase in co-operation and networking within the research system exist (Hicks and Katz, 1996). The formation of a collaboration between researchers is dependent on their cognitive backgrounds and on social and economic considerations (Traore and Landry, 1997; Luukkonen et al., 1992). Moreover, the frequency of interaction between researchers plays a role (Hagstrom, 1965; Katz and Martin, 1997). Kraut et al. $(1987,1990)$ argue that frequent communication provides opportunities for an easy assessment of the qualities of a potential co-operation partner. These opportunities to make a preliminary assessment may also be given in active IDGs.

Accordingly, one of the important possibilities given by IDGs is to make or stay in contact with other researchers. IDGs are expected to create new links or to intensify existing ties between researchers.

In particular, possibilities for the creation of new links have attracted many analysts' attention. They think that this potential benefit of IDGs has important consequences not only for the individual researcher. Rather, they studied the impact on the macro level of the whole communication network of a research field. Some expect that IDGs might be a remedy for existing problems and disadvantages within the informal communication structures of research fields (e.g. Hiltz and Turoff, 1978).

Traditionally, the informal communication structure in a research field is characterized by "invisible colleges" which consist of a small number of very active researchers who regularly exchange information or papers related to the newest progress on the research front (Price, 1963; Crane, 1972; Lievrouw, 1990). Such invisible colleges have been found in a variety of different disciplines within the natural sciences, the social sciences, and the humanities (e.g. Price and Beaver, 1966; Crane, 1969; Crane, 1972; Gaston, 1972; Zaltman, 1974; Weedman, 1993). They mediate large fractions of the informal communication within many research fields. As a result of its limited size and restricted access opportunities, the existence of an invisible college leads to an unequal distribution of communication possibilities. There is a status hierarchy which is directly linked to the opportunities for access to communication channels. Those few very active researchers at the center of an invisible college have the most possibilities (Price and Beaver, 1966; Price, 1971). The large number of researchers who do not have access to any member of an invisible college have very few communication opportunities (Garvey and Griffith, 1966). This affects younger researchers in particular, who are prevented from reaching their full potential, and thus from making the maximum possible contribution to their discipline (Cronin, 1982). 
Proponents of IDGs hope that IDGs enhance the information flow between low-status and high-status researchers and that, in particular, disadvantaged researchers will profit from the opportunities for creating new contacts (Hiltz and Turoff, 1978). IDGs could thereby, it is hoped, counteract the Matthew Effect in science (Merton, 1973) which postulates that those in the research system who are already recognized will cumulatively be more advantaged compared to those who are less recognized. Researchers have different expectations concerning the extent to which this inequality will be diminished. These hopes for equalizing effects on the academic communication network, which I summarize here as the "equality hypothesis", are expressed in two different forms.

Some researchers expect a peripherality effect from those computer-mediated communication tools for which there are hardly any access restrictions (Hesse et al., 1993; Walsh and Bayma, 1996b). ${ }^{5}$ Peripheral researchers, e.g. younger researchers and those at less prestigious institutions, will be more able to participate in the informal communication system of a research field through the use of these CMC tools. They will extend their communication networks (Walsh and Bayma, 1996b). The peripherality hypothesis does not predict sweeping changes in the significance of a researcher's status for control over access opportunities to informal communication channels. It leaves open the questions of whether there are any substantial effects for well-integrated researchers and whether the differences in the effects of IDGs for peripheral and integrated researchers will be large enough to have a fundamental impact on the inequality in the distribution of communication opportunities (ibid.). ${ }^{6}$ However, it suggests an effect that reduces the inequality at least to some degree (Walsh, 1998).

A strong form of the hope for a reduction of inequality is expressed by Gresham (1994). He predicts that IDGs will extend the contact network of researchers in general. Invisible colleges will increase in size and their exclusiveness will be overcome through IDGs. The character of invisible colleges will be changed fundamentally because their elitism will disappear. Those who are less integrated will particularly profit from these new opportunities because IDGs allow them to make contact with experts in their research field.

Accordingly, both forms imply a reduction of inequality in the opportunities for access to communication channels (equality hypothesis). Those who are less integrated in informal networks will profit disproportionately from the opportunities which IDGs offer for the creation of new contacts. However, the two forms differ in relation to the expected scope of this reduction. Whereas the peripherality hypothesis involves only some reduction, the strong equality hypothesis predicts a very clear reduction of inequality with regard to contacts of fundamental importance.

The empirical evidence for the contact benefits of IDGs is weaker than the evidence for the information and idea benefits. Lubanski and Matthew (1998) and Ziesemer (1996)

\footnotetext{
${ }^{5}$ Free access to CMC tools such as E-Mail and IDGs is practically taken for granted for west-European and US-researchers.

${ }^{6}$ Furthermore, Walsh and Bayma (1996b, 357) explicitly mention another scenario. They note that top researchers may profit more because they are the target of those researchers who initiate E-Mail-contact in hopes of collaboration. However, the only differential effects found were greater for peripheral researchers (see below). Moreover, Walsh (1998) refers to the peripherality hypothesis as implying that peripheral researchers profit disproportionately.
} 
give some examples of researchers who created new contacts through the use of Internet tools (including IDGs). Hiltz (1984) found in her study of four research groups using a computer conference system that intensive system use increased the communication between the researchers. Freeman (1984) studied the use of an electronic conference system by a small number of social network researchers. He found that during the seven months of system use, the mutual awareness and mutual acquaintance between pairs of researchers increased. Rojo and Ragsdale (1997a) found in their study of eleven mailing lists that only a minority of researchers (37 out of 124) had become more aware of other researchers. Lewenstein (1995) reports only limited possibilities for the creation of new contacts between researchers in one physics newsgroup studied. None of these studies compared users of IDGs with non-users or distinguished peripheral researchers from more integrated ones. Scholl et al. (1996) asked researchers whether E-Mail use led to an intensification of contacts with other researchers. They found that those who were intensive E-Mail and IDG users attributed a significantly higher value to its usefulness for the intensification of contacts than less intensive users. Cohen (1996) found in his study that the more intensively the faculty used IDGs, the more positively they assessed "... how electronic mail and network access have benefited... scholarly activities..." with regard to "enhanced contact" and the "ability to collaborate with colleagues at other campuses" (ibid., 56).

Hesse et al. (1993) made a distinction between different groups of researchers. They studied the use of computer networks (including IDGs) by 257 researchers within the field of oceanography. In a multivariate analysis, they found positive associations between CMC use and the number of published articles, the degree of professional recognition, and the number of oceanographers known by the respondent. The first two effects were stronger for researchers at peripheral research institutes or for less experienced researchers. Later studies of the general use of CMC found positive associations between the use of CMC tools and the degree of collaboration between researchers. However, stronger effects of general CMC use for peripheral researchers were not always found (Cohen, 1996; Walsh, 1998).

Other analyses investigate the effects of general E-Mail use on the creation of new contacts or for the maintenance of existing contacts between researchers. Carley and Wendt (1991) studied a small group of researchers at geographically dispersed locations. They found that E-Mail was used to enhance existing contacts but not to create new ones. Meadows and Buckle (1992) also argue that the use of E-Mail for informal communication by British researchers did not reduce social barriers to the circulation of important pieces of information such as pre-prints of research papers. Other studies found that researchers use E-Mail often for the maintenance of existing friendship contacts (see e.g. Haythornwaite and Wellman, 1998; Koku et al., 2001).

This data does not allow us to draw any firm conclusions. The existing evidence often suffers from the same drawbacks as the evidence for information benefits. It is not clear whether IDGs lead to an increase in informal contacts among researchers. Furthermore, it is unclear whether there are differential effects that reduce existing inequalities. Contact benefits, even for a limited group of researchers, could be important for the research system. However, it remains unclear what benefits these hypothetical new contacts may have and for whom. Are they opportunities for posing single questions, or can they become more regular 
information channels? There is no information about the nature of contacts. However, a distinction between different kinds of contacts is necessary in order to test the two forms of the hypothesis that there will be equalizing effects.

\subsection{The potential and its realization: the hypotheses}

The purpose of this study is to test in a systematic way the general hypothesis that there are some information or contact benefits for researchers who are regular IDG users. ${ }^{7}$ This does not imply a technological determinism. Rather, I analyze whether the potential of this communication technology is indeed being realized to some degree by researchers at the end of the 1990s. I distinguish a number of specific benefits to find out what specific relevance these different potential benefits have. I test the association between IDG use and these benefits, controlling for the influence of a number of other possible factors. The wording of the items used for the measurement of the benefits ("the effects") is not related to the use of IDGs ("the potential cause") or other forms of CMC.

The general hypothesis of IDG benefits is divided into some more specific sub-hypotheses. Among the information benefits, I make a distinction between research information benefits which apply to the researcher's most important research field and practical, helpful information benefits that are useful for solving practical problems related to the conduction of a research project. This distinction makes a difference between information items related to the content of a research community (e.g. knowledge about the content of research literature) and information items about procedures that are only instrumental for receiving information (e.g. knowledge about how to retrieve research literature efficiently). The contact benefits include contacts that make a researcher's work more visible to others or that make himself more aware of other researchers' work (weak contacts), contacts leading to the reception of new research papers and articles (reception contacts) and contacts relating to collaborative work (strong contacts).

Obviously, not only the use of IDGs can affect these benefits. Other research has shown that these benefits depend on to what degree the researcher's work is already visible to other researchers (Cole and Cole, 1968), on differences in the scholars' activity in research (e.g. Price and Beaver, 1966), on how actively researchers are looking for information and for contacts and on how frequently they communicate and collaborate with other researchers in general (e.g. Becher, 1989). Many of these aspects of a researcher's communication behavior vary between researchers of different disciplines (Whitley, 1984; Becher, 1989). Moreover, in order to find out whether it is really the use of the IDG that matters and not the use of E-Mail or other CMC tools, one also has to control for differences in the use of other CMC tools. Finally, there might be differences between university departments. Researchers at prestigious departments might be more visible than researchers at less prestigious departments (Cole and Cole, 1968). The hypotheses state that the opportunities offered by IDGs determine these benefits because researchers make use of these opportunities. Thus, one should find a positive association between these opportunities and the five different potential benefits after controlling for these other possible factors of influence.

\footnotetext{
${ }^{7}$ I did not test hypotheses about the generation of ideas through IDGs. Such tests are difficult to conduct among respondents of a large random sample.
} 


\begin{tabular}{|c|c|c|}
\hline $\begin{array}{l}5 \text { hypotheses at the level of the } \\
\text { individual researcher }\end{array}$ & \multicolumn{2}{|c|}{$\begin{array}{l}2 \text { hypotheses about inequality reducing effects at the } \\
\text { level of the communication networks }\end{array}$} \\
\hline general benefits & strong equality hypothesis & peripherality hypothesis \\
\hline $\begin{array}{l}\text { 1. Research information } \\
\text { benefits }\end{array}$ & no prediction & \\
\hline $\begin{array}{l}\text { 2. Practical helpful } \\
\text { information benefits }\end{array}$ & no prediction & \\
\hline 3. Weak contact benefits & no prediction & $\begin{array}{l}\text { at least one stronger } \\
\text { effect for peripheral }\end{array}$ \\
\hline 4. Reception contact benefits & $\begin{array}{l}\text { stronger effect for peripheral } \\
\text { researchers than for well- } \\
\text { integrated researchers }\end{array}$ & integrated researchers \\
\hline 5. Strong contact benefits & $\begin{array}{l}\text { stronger effect for peripheral } \\
\text { researchers than for well- } \\
\text { integrated researchers }\end{array}$ & \\
\hline
\end{tabular}

Fig. 1. The hypotheses.

Accordingly, at the level of the individual researcher I test two information hypotheses and three contact hypotheses. These hypotheses represent the expectation that there are benefits at the level of the individual researcher. Moreover, I test whether there are inequality-reducing effects at the level of the informal communication network. For all five hypotheses I test whether there are differential benefits for peripheral and better-integrated researchers.

A direct test of the strong form of the equality hypothesis, namely that access restrictions to invisible colleges are reduced in a fundamental way, would need a snowball sampling of invisible college members. This is not feasible for a large random sample of university researchers. However, this paper tests the strong equality hypothesis in another way. If this hypothesis holds, one should find contact effects for peripheral researchers that lead to an extension of their regular social networks in such a way that their relative disadvantages with regard to these contacts are clearly diminished. That is, one should find stronger effects for peripheral than for integrated researchers relating to their reception contacts and strong contacts (strong equality hypothesis). If the weaker peripherality hypothesis is true, then some effect(s) relating to any of the opportunities should be found among peripheral researchers who use IDGs and the effect(s) should be stronger than the effects(s) for integrated researchers. The peripherality hypothesis implies at least one differential effect. It does not specify which of the effects should be greater for peripheral than for integrated researchers, whereas the strong equality hypothesis implies both a differential reception contact effect and a differential strong contact effect. Section 3 describes how the term "peripherality" is used in this study.

Thus, this study tests seven hypotheses. Five of them are related to the level of the individual researcher and two hypotheses are related to the level of the informal communication network. Fig. 1 gives an overview of the hypotheses. 


\section{The data}

\subsection{Design and measurements}

The hypotheses are tested by using the answers to a postal questionnaire sent to a multi-stage random sample of English and Dutch university researchers in the following disciplines.

- History

- Sociology

- Management science

- Economics

- Mathematics

- Mechanical engineering

- Chemistry

- Physics

The study population contains researchers, including Ph.D. students and postdoctoral researchers, who are doing research at a university department in the Netherlands or England within one of these eight disciplines. I chose all 13 universities within the Netherlands. Within England 23 universities were randomly selected. Within every selected university I chose all departments that belong to one of the eight disciplines. ${ }^{8}$ Within every selected department a random sample of the researchers was taken-with one exception. A small number of departments had a very high proportion of Ph.D. students. In such departments I sampled researchers with a non-temporary position disproportionately often to ensure that the sample contained a large enough number of them.

The questionnaire contained items relating to the general communication behavior of the researchers, detailed questions about their contact networks, their use of IDGs and other CMC tools, in addition to questions about their research activities. Moreover, I asked a number of questions that were especially related to the field of research wherein the respondent is most active. The data was collected from September 1998 until March 1999. A total of 1063 out of 2688 researchers returned a usable questionnaire $(\sim 40 \%)$. Filling in the questionnaire took approximately $45-60 \mathrm{~min}$. By far the most frequently mentioned reason for non-participation was a shortage of time. The response rate does not differ between Dutch and English respondents $(P>0.9)$. It does not differ between respondents of different disciplines, with the one exception of mechanical engineers who answered significantly less often. A total of $30.4 \%$ of them sent back a completed questionnaire (chi-square $=15.1$, d.f. $=7, P<0.05$ for all eight disciplines and chi-square $=5.2$, d.f. $=6, P>0.45$ for the remaining seven disciplines).

The respondents were asked to mention the names of at most five important mailing lists or newsgroups that they use for professional reasons. For every IDG they had to estimate the average monthly number of messages sent to the IDG and the duration of their own membership in months. Moreover, I asked the researchers whether the used IDGs had any

\footnotetext{
8 Among the larger disciplines with more than one department at the same university, only those departments which cover some core research areas within that discipline were selected (see Matzat (2001) for the details).
} 
relevance at all for their research field. The final analysis included only those IDGs that were denoted to be relevant by the respondent, and that the respondent had used for at least two months.

\subsubsection{Main explanatory variable}

I constructed an index of the opportunities offered by IDGs. This index has five categories and is based on the average total number of the monthly messages sent to all relevant IDGs that the respondent uses. The higher this total number of messages, the greater on average are the opportunities for contact and information benefits. ${ }^{9}$ Accordingly, I test whether these opportunities are really large enough to result in some benefits within the study population of Dutch and English university researchers.

The peripherality of a researcher indicates that the researcher has no more than a moderate number of contacts with other researchers relating to the regular exchange of written research papers. I asked the respondents to estimate how often during the previous 12 months they had reviewed manuscripts for a journal, to how many other researchers they had sent a manuscript of an as yet unpublished research paper, and how many published articles and unpublished research papers they had received from other researchers without having to ask for them. The respondents were ranked within their discipline on each of these four variables. The peripherality-integration index consists of the first principal component that results from a PCA analysis on these four ranking variables (see Appendix A).

For the construction of an interaction variable measuring the IDG induced opportunities for peripheral researchers, the respondents were divided into two equal-sized groups of peripheral and well-integrated researchers based on this principal component. The dichotomous variable was then multiplied by the IDG index. Interactions of peripherality with other variables were constructed in the same way.

\subsubsection{Dependent variables}

Research information benefits are related to questions about the following aspects of the respondents' research field. ${ }^{10}$

- the most important literature;

- the newest "progress on the research front";

- the names of the currently most active researchers;

- conferences that are actually taking place.

The respondents had to assess on seven point Likert scales how well informed they were about these aspects. The scores were standardized within every discipline to avoid variance heterogeneities and differences in the means between the disciplines. These four scores were combined into one variable by using the first component in a principal component analysis (see the appendix for details). As a result, the analyses compare the researcher only with other researchers within his discipline.

\footnotetext{
9 The coding was done separately for the number of messages sent to a newsgroup or to a mailing list to avoid bias caused by the higher number of messages sent to newsgroups. The selection of a subset of IDGs ensures that the respondent is somewhat familiar with the IDG and that the analysis concentrates only on those IDGs that are research oriented and are considered to be of reasonable quality.

10 The reader can find a detailed description of the items in Appendix A.
} 
Practical, helpful information benefits include the following.

- access possibilities to collegial expert knowledge when it is needed

- avoidance of research delays caused by such access difficulties, relating to practical problems (e.g. literature retrieval problems, software difficulties, special technical problems), or caused by finding important pieces of published or unpublished literature too late

The first variable consists of a self-estimation on a seven point Likert scale of how easy it was for the researcher to gain access to the assistance of colleagues when he needed it. The second variable is dichotomous and indicates the occurrence of a research delay during the previous 12 months either because the respondent found an important piece of literature too late or because it was impossible to gain access to the assistance of colleagues when needed. I test whether there is a negative effect of IDG use on the probability of this occurrence.

Potential weak contact benefits are related to

- being personally asked by other researchers for research papers and publications;

- having personally asked other researchers for research papers and publications;

- approaching (or being approached by) other researchers with some regularity for a professionally useful information transfer.

I asked the respondents to estimate the frequency of occurrences of these three events during the previous twelve months (see Appendix A). The distributions of these three variables were skewed because in every discipline there are some respondents who mentioned very large numbers. Therefore, I took the natural logarithms of the numbers (added by one). A principal component analysis was conducted to compute the first component of these three correlated variables (see Appendix A for the details). This principal component is the dependent variable for the analysis of the weak contacts.

By reception contacts I mean contacts leading to the reception of other researchers' published articles or unpublished research papers that the respondent actively asked for during the previous 12 months. Because of the distributions, I computed for each of the two variables (the number of received articles and the number of unpublished papers received) a ranking within every discipline, and then took the mean of these two discipline-specific rankings. This variable was dichotomized at the median. The dichotomization was done to avoid a skewed distribution of the dependent variable caused by the high number of researchers who hardly got any manuscripts or articles. ${ }^{11}$ This dichotomized variable is the interesting variable in the analysis of reception contacts.

Finally, strong contacts are defined as implying

- collaborative work with other researchers outside one's own department or

- collaborative work with other Ph.D. students outside one's own department.

The dependent variable for the analysis consists of the occurrence of at least one of these collaborations. ${ }^{12}$

\footnotetext{
11 A linear regression analysis with the original variable led to a stronger main IDG effect. The analysis of residuals, however, indicated influential outliers that might have biased the estimation.

12 The conclusions do not change when I analyse separately the two variables.
} 
The reader has to take into account that many variables are based on the respondents' self-reports which may be subject to measurement error. The questionnaire avoided vague quantifiers in questions about frequencies. Instead, it used open-format questions, when possible, to reduce systematic influences of the quantifiers (Schwarz, 1999). Nevertheless, the existence of some degree of measurement error is possible. For example, existing research (Deane et al., 1998) indicates only a moderate to strong correlation between self-ratings of Internet use and electronic log estimates of frequency and duration of system use.

\subsection{Descriptive findings}

Table 1 shows the distribution of the respondents with regard to discipline and their university position. The large proportion of Ph.D. students and post doc researchers was intended to ensure that there is a large number of peripheral researchers. However, peripherality does not necessarily imply having a temporary research position within the university department.

The proportion of respondents who have an E-Mail connection and thus have the possibility of using IDGs is $97 \%$ (not shown in the tables). This proportion is lower among history researchers $(90.6 \%)$, but does not differ significantly between the other disciplines. As Table 2 reveals, the frequency of IDG use differs between the disciplines. A total of $23.3 \%$ or 244 of all respondents say that they use at least one IDG for professional reasons. IDG use is most common within management science, sociology, and mathematics. It is least common in physics and chemistry. Moreover, $5.1 \%$ of all respondents had used an IDG in the past, but had stopped using it (not shown in Table 2).

Table 1

Discipline and position

\begin{tabular}{lcr}
\hline & Frequency & Valid percent \\
\hline (A) Discipline & & 13.6 \\
History & 144 & 11.7 \\
Management science & 124 & 13.1 \\
Sociology & 139 & 13.4 \\
Economics & 142 & 7.4 \\
Mechanical engineering & 79 & 12.1 \\
Mathematics & 129 & 14.7 \\
Chemistry & 156 & 14.1 \\
Physics & 150 & 100.0 \\
Total & 1063 & 38.0 \\
(B) Position & & 9.6 \\
Ph.D. student & 402 & 27.5 \\
Post-doc & 101 & 9.2 \\
Assistant Professor & 291 & 15.7 \\
Associate Professor & 97 & 0.6 \\
Professor & 166 & 100.0 \\
Missing & 6 & \\
Total & 1063 & \\
\hline
\end{tabular}


Table 2

IDG membership

\begin{tabular}{lcc}
\hline Discipline & Sample size & Percentage of IDG users \\
\hline Whole sample & 1063 & 23.3 \\
History & 144 & 22.9 \\
Management science & 124 & 34.5 \\
Sociology & 139 & 33.3 \\
Economics & 142 & 27.9 \\
Mechanical engineering & 79 & 19.0 \\
Mathematics & 129 & 32.3 \\
Chemistry & 156 & 11.5 \\
Physics & 150 & 8.1 \\
\hline
\end{tabular}

The numbers of cases in the analyses differ from these numbers because of the list-wise deletion of missing values.

Mailing lists are used much more often than newsgroups. Only 3\% of all respondents claim to use at least one newsgroup $(n=31)$, whereas $18.4 \%$ claim to use at least one mailing list $(n=191) .{ }^{13}$ The use of newsgroups is almost exclusively restricted to researchers within mathematics (10\% of all mathematicians), mechanical engineering $(9 \%)$ and physics $(3 \%)$. Only 19 respondents ( $61 \%$ of the newsgroup users) claim to use a newsgroup but no mailing list. On the other hand, $94 \%$ of the mailing list users do not use a newsgroup. A newsgroup user makes use of, on average, more newsgroups $(\bar{X}=2.6)$ than a mailing list user makes use of mailing lists $(\bar{X}=1.7)$. The difference is significant $(P<0.01) .{ }^{14}$ Out of the 61 references to newsgroups (many of them being mentioned several times) $26.3 \%$ were evaluated as having no relevance for the respondent's main research field. Only $12.5 \%$ of the 328 references to mailing lists (many of them being mentioned several times) were evaluated as having no relevance. This difference is also significant (chi-square $=7.75$, d.f. $=1, P<0.01$ ).

These numbers show that one cannot expect any extensive equalizing effects for academic communication from the use of newsgroups alone. Newsgroups alone cannot reduce inequalities in the distribution of communication opportunities because only a very small minority of researchers in certain disciplines use them. Moreover, many of them are regarded to be completely irrelevant to the main research activities of the respondents.

The following analyses include only those IDGs that were evaluated as having relevance. Because of the low number of newsgroup users, I did not conduct separate analyses for the two types of IDGs. Table 3 shows some descriptive findings for the dependent variables of the analyses.

The used variables relating to the research information benefits and to the reception contacts are transformed in such a way that differences between the disciplines with regard to means and variances are eliminated. The original variables showed significant differences in the means of the absolute numbers between disciplines, especially for the reception contacts. They were highest for researchers within economics, physics and management

\footnotetext{
13 The numbers do not add up to 244 because of missing values.

14 I conducted the Mann-Whitney $U$-test for the groups of researchers that either use newsgroups or mailing lists. The additional 12 researchers who are both mailing list and newsgroup users make use of on average the same number of mailing lists and newsgroups, namely 1.8 .
} 
Table 3

Dependent variables

\begin{tabular}{|c|c|c|c|c|c|c|c|c|c|}
\hline Variable & $\begin{array}{l}\text { Whole } \\
\text { sample }\end{array}$ & History & $\begin{array}{l}\text { Management } \\
\text { science }\end{array}$ & Sociology & Economics & $\begin{array}{l}\text { Mechanical } \\
\text { engineering }\end{array}$ & Mathematics & Chemistry & Physics \\
\hline Ease of access & $\begin{array}{l}\bar{X}=4.94, \\
S=1.51\end{array}$ & $\begin{array}{l}\bar{X}=5.01 \\
S=1.57\end{array}$ & $\begin{array}{l}\bar{X}=4.82 \\
S=1.57\end{array}$ & $\begin{array}{l}\bar{X}=5.04, \\
S=1.47\end{array}$ & $\begin{array}{l}\bar{X}=4.62 \\
S=1.61\end{array}$ & $\begin{array}{l}\bar{X}=4.63 \\
S=1.57\end{array}$ & $\begin{array}{l}\bar{X}=5.1 \\
S=1.32\end{array}$ & $\begin{array}{l}\bar{X}=5.09 \\
S=1.53\end{array}$ & $\begin{array}{l}\bar{X}=5.04 \\
S=1.43\end{array}$ \\
\hline Delay (dichotomized) & $P=0.35$ & $P=0.28$ & $P=0.38$ & $P=0.35$ & $P=0.44$ & $P=0.39$ & $P=0.30$ & $P=0.34$ & $P=0.31$ \\
\hline Weak contacts & $\begin{array}{l}\bar{X}=0 \\
S=1\end{array}$ & $\begin{array}{l}\bar{X}=-0.14 \\
S=0.96\end{array}$ & $\begin{array}{l}\bar{X}=0.07 \\
S=0.91\end{array}$ & $\begin{array}{l}\bar{X}=0.15, \\
S=0.99\end{array}$ & $\begin{array}{l}\bar{X}=0.22 \\
S=1.04\end{array}$ & $\begin{array}{l}\bar{X}=-0.37 \\
S=0.81\end{array}$ & $\begin{array}{l}\bar{X}=0.16 \\
S=1.02\end{array}$ & $\begin{array}{l}\bar{X}=-0.41 \\
S=0.99\end{array}$ & $\begin{array}{l}\bar{X}=0.20 \\
S=0.99\end{array}$ \\
\hline $\begin{array}{l}\text { Strong contacts } \\
\text { (dichotomized) }\end{array}$ & $P=0.69$ & $P=0.48$ & $P=0.66$ & $P=0.73$ & $P=0.72$ & $P=0.74$ & $P=0.70$ & $P=0.68$ & $P=0.83$ \\
\hline
\end{tabular}

The variable reception contact is ranked within every discipline and dichotomized at the median within the groups of peripheral and well-integrated researchers. The variable research information benefits is standardized within every discipline $(\bar{X}=0, S=1)$. For the dichotomized variables holds $\bar{X}=P$ and $S=P \times(1-P)$. 
science, and lowest for researchers in history, sociology (only for the number of articles) and chemistry (only for the number of manuscripts). Table 3 shows that with regard to the practical information benefits there are no mean differences for the ease of access to the assistance of colleagues. The mean score is 4.9 on a scale from 1 (very difficult) to 7 (very easy), which implies that this access is moderately easy. There are some disciplinary differences in the occurrence of at least one research delay, which takes place most often among researchers within economics, management science and mechanical engineering. There are clear differences relating to weak and strong contacts. In particular, researchers within physics, sociology, mathematics and economics score, on average, higher on the weak contact scale whereas chemists and engineers score lower. Moreover, the occurrence of collaboration differs between disciplines. Many more researchers within physics work collaboratively and many fewer historians do so.

Researchers who use IDGs visit more conferences $(t=3.1$, two-sided $P<0.01)$, use E-Mail more often $(t=6.7, P<0.01)$, are more intensive world-wide-web users $(t=4.8$, $P<0.01)$, use the file transfer protocol barely more frequently $(t=1.53, P=0.13)$ and work more often with a computer $(t=3.4, P<0.01)$ than researchers who do not use IDGs. The proportion of IDG users does not depend on age $(t=1.25, P=0.2)$ and does not differ between men and women $(t=0.42, P=0.7)$ or between Dutch and English researchers $(t=0.94, P=0.35)$.

\subsection{Analysis methods}

I test the hypotheses relating to the information and contact benefits by using multiple linear regression analyses or multiple logistic regression analyses. ${ }^{15}$ To find out whether the potential effects of IDG use are spurious and due to, for example differences between the researchers' prominence and in their already existing contacts with other researchers (see section 2.3), I control for influences of the researchers' embeddedness in informal contact networks, their research activities, their research experience, their general communication behavior, and their prominence. Moreover, to find out whether it is the use of IDGs that matters, and not just the general use of E-Mail or other information technologies, I also control for the use of other CMC tools. Accordingly, the following seven control variables are included in the analyses: ${ }^{16}$ general use of CMC (CMC), general frequency of communication with other researchers, the respondents' prominence, their integration in existing informal networks (INTEGRATION), their research experience, their conference participa-

\footnotetext{
15 These tests include only those respondents who are active researchers in the sense that they have written at least one research paper during the previous three years $(n=902)$. Moreover, the actual case numbers in the regression analyses depend on the number of missing values (see tables). The reported $P$-values correspond to two-sided tests, unless otherwise stated.

16 The variables are described in more detail in the appendix. Additionally, by using multilevel analyses I control for possible differences between the departments, which might affect the dependent variables. I constructed a number of possible indicators which are based on the mean values of relevant independent variables of the associate professors, assistant professors and professors of the same department (e.g. mean number of written articles, mean value of integration in communication networks, mean number of supervised $\mathrm{Ph}$.D. students). None of them had a significant effect after including the other control variables at the individual level. The same was true for potential differences between universities.
} 
tion (\#CONFERENCES), and their written research output (\#PAPERS). I include dummy variables to control for disciplinary differences in the values of those dependent variables that are not transformed in such a way to remove disciplinary differences. As a consequence, the analysis focuses on differences between researchers of the same discipline. Moreover, I include an interaction variable to test whether there are smaller effects for the group of well-integrated researchers than for peripheral researchers, as predicted by the equality hypotheses. Because this is sometimes also predicted for the use of CMC tools in general, every analysis tests for at least two interaction effects, namely differential IDG effects and differential general CMC effects.

I started every regression analysis with two separate regressions for the groups of peripheral and well-integrated researchers in order to find out whether there are other effects of the control variables that might also differ for these groups. The second step of the analysis consisted of one regression analysis for both groups of researchers. If there was an effect of a control variable that potentially differed between the two groups, then the corresponding interaction term was included in this regression model. Every potentially significant difference between the two groups was taken into account by an additional interaction effect to avoid an incorrect specification of the final regression model. The final model of the third step of the analysis contains only the significant interaction effects. Accordingly, it has eight main effects (and additional dummy variables for disciplinary differences when needed). Additional interaction variables for differential effects of the control variables or differential IDG or CMC effects between peripheral and well-integrated researchers were included only when needed.

\section{The results}

The following tables show the final results for every regression analysis. If the interaction effects for CMC and IDG use were shown to be insignificant during the second step of an analysis, then they are not included in the final model. Instead, the estimated interaction effects of the second step are reported at the bottom of the table.

I first analyze the effects of IDG use on potential research information benefits, that is on how well informed researchers feel they are about different aspects of their research community. Six out of the eight main effects are significant. The whole model 'explains' $33.3 \%$ of the variance of research information benefits.

Most importantly, the IDG index which indicates the quantity of monthly-received IDGE-mails has a significant positive main effect $(P=0.01)$. The size of the effect is moderate (beta $=0.07$ ) when compared to that of a researchers' prominence (beta $=0.44$ ) or the number of visited conferences (beta $=0.34$ ). However, this effect of IDG use on research information benefits cannot be explained by the use of other CMC tools such as the general use of E-Mail or the use of the world wide web. ${ }^{17}$

\footnotetext{
17 Separate regressions on the four within-discipline $z$-scores for the component items show that the IDG effect on research information benefits is mainly due to effects on being "informed about the names of the currently most active researchers" and being "informed about ongoing conferences...".
} 
Table 4

Research information advantages

\begin{tabular}{|c|c|c|c|}
\hline Variable & $B$ & Beta & $T$ \\
\hline \multicolumn{4}{|l|}{ Main effects } \\
\hline IDG & $0.069^{* *}$ & 0.074 & 2.58 \\
\hline $\mathrm{CMC}$ & $0.073^{*}$ & 0.073 & 2.43 \\
\hline Communication frequency & $0.067^{* * *}$ & 0.104 & 3.39 \\
\hline Prominence & $0.252^{* * *}$ & 0.439 & 12.05 \\
\hline Research experience & -0.004 & -0.045 & -1.30 \\
\hline \#Conferences & $0.080^{* * *}$ & 0.344 & 4.45 \\
\hline \#Papers & 0.010 & 0.036 & 1.09 \\
\hline Integration & $0.184^{* * *}$ & 0.186 & 4.49 \\
\hline \multicolumn{4}{|l|}{ Interaction effects } \\
\hline \multicolumn{4}{|l|}{ Well-integrated $\times \ldots$} \\
\hline$\ldots \times \#$ Conferences & $-0.080^{* * *}$ & -0.339 & -4.11 \\
\hline \multicolumn{4}{|c|}{ Adjusted $R^{2}=0.333$, d.f. $1=9$, d.f. $2=817, n=827, F=46.85 P=0.00$} \\
\hline \multicolumn{4}{|c|}{$\begin{array}{l}\text { Additional non-significant interaction effects which are not part of the final model } \\
\text { Well-integrated } \times \ldots\end{array}$} \\
\hline$\ldots \times$ IDG & -0.010 & -0.008 & -0.19 \\
\hline$\ldots \times \mathrm{CMC}$ & 0.024 & 0.020 & 0.41 \\
\hline $\begin{array}{l}\text { Constant not shown, interactic } \\
\qquad{ }^{*} P<0.05 \\
\quad{ }^{* *} P<0.01 \\
\quad{ }^{* * *} P<0.001\end{array}$ & riables center & & \\
\hline
\end{tabular}

It is not surprising that better integrated researchers, more prominent researchers, those who visit more conferences, those who are more intensive CMC users, or who communicate more frequently with colleagues about their research have higher scores on the scale of research information benefits. The results with regard to the interaction effects show that the effect of the number of visited conferences is significantly smaller for well-integrated than for peripheral researchers (Table 4).

Another important finding is the non-significant interaction effect of IDG use $(P=0.85)$. It shows that peripheral researchers do not profit more or less from the opportunities offered by IDGs than well-integrated researchers. The peripherality hypothesis is clearly not confirmed with respect to research information benefits.

Table 5 shows the results of the multiple linear and logistic regressions on the two variables relating to practical, helpful information benefits.

Only very few of the variables can explain some variance in the perceived ease of access to assistance of colleagues. IDG use shows no significant effect, for peripheral or integrated researchers. The frequency of general communication and the degree of integration show clear positive effects, which comes as no surprise. Researchers who discuss their research more often with colleagues and those who are better integrated find it easier to obtain help in case of problems.

Differences in the probability of the occurrence of delays during a research project cannot be explained very well by the variables either. Most importantly, the use of IDGs does 
Table 5

(A) Access to helping knowledge

\begin{tabular}{lcrr}
\hline Variable & $B$ & Beta & $T$ \\
\hline Main effects & & 0.003 & 0.08 \\
$\quad$ IDG & 0.005 & -0.020 & -0.42 \\
CMC & -0.024 & 0.154 & 3.87 \\
Communication frequency & $0.154^{* * *}$ & 0.071 & 1.49 \\
Prominence & 0.063 & 0.050 & 1.10 \\
Research experience & 0.008 & 0.094 & 1.64 \\
\#Conferences & 0.060 & 0.030 & 0.67 \\
\#Papers & 0.010 & 0.119 & 2.05 \\
Integration & $0.180^{*}$ & & -2.27 \\
Interaction effects & & & \\
$\quad$ Well-integrated $\times \ldots$ & & -0.160 &
\end{tabular}

Adjusted $R^{2}=0.05$, d.f. $1=9$, d.f. $2=683, n=693, F=4.79, P=0.000$

Additional non-significant interaction effects which are not part of the final model Well-integrated $\times \ldots$
$\ldots \times$ IDG
$-0.019$
$-0.01$
$-0.18$
$\ldots \times \mathrm{CMC}$
0.080
0.037

(B) Delay

\begin{tabular}{|c|c|c|}
\hline Variable & $B$ & Wald $($ d.f. $=1)$ \\
\hline \multicolumn{3}{|l|}{ Main effects } \\
\hline IDG & 0.080 & 1.59 \\
\hline $\mathrm{CMC}$ & 0.080 & 0.99 \\
\hline Communication frequency & -0.064 & 1.17 \\
\hline Prominence & -0.100 & 2.96 \\
\hline Research experience & $-0.029^{* *}$ & 6.1 \\
\hline \#Conferences & $0.130^{* *}$ & 5.98 \\
\hline \#Papers & 0.001 & 0.001 \\
\hline Integration & 0.020 & 3.16 \\
\hline \multicolumn{3}{|l|}{ Interaction effects } \\
\hline \multicolumn{3}{|l|}{ Well-integrated $\times \ldots$} \\
\hline$\ldots \times \#$ Conferences & $-0.130^{*}$ & 5.38 \\
\hline \multicolumn{3}{|c|}{ Model $\chi^{2}=34.51$, d.f. $=16, n=813, P=0.004$} \\
\hline \multicolumn{3}{|c|}{$\begin{array}{l}\text { Additional non-significant interaction effects which are not part of the final model } \\
\text { Well-integrated } \times \ldots\end{array}$} \\
\hline$\ldots \times$ IDG & 0.060 & 0.14 \\
\hline$\ldots \times \mathrm{CMC}$ & -0.020 & 0.01 \\
\hline
\end{tabular}

Constant and dummy variables for the disciplines not shown, interaction variables centered; for Table $5 \mathrm{~A}$ analysis restricted to respondents who were in need of access to helping knowledge (see Appendix).

$$
\begin{aligned}
& { }^{*} P<0.05 . \\
& { }^{* *} P<0.01 . \\
& { }^{* * *} P<0.001 .
\end{aligned}
$$


Table 6

Weak contacts

\begin{tabular}{lcrr}
\hline Variable & $B$ & Beta & $T$ \\
\hline Main effects & & & 0.073 \\
IDG & $0.067^{* *}$ & 0.075 & 2.64 \\
CMC & $0.074^{* *}$ & 0.176 & 2.60 \\
Communication frequency & $0.110^{* * *}$ & 0.121 & 5.84 \\
Prominence & $0.068^{* *}$ & -0.055 & 3.42 \\
Research experience & -0.005 & 0.143 & -1.67 \\
\#Conferences & $0.060^{* * *}$ & 0.085 & 4.87 \\
\#Papers & $0.027^{* *}$ & 0.389 & 2.69 \\
Integration & $0.378^{* * *}$ & 11.53 \\
Adjusted $R^{2}=0.43$, d.f. $1=15$, d.f.2 & 781, $n=797, F=41.57, P=0.000$ & \\
Additional non-significant interaction effects which are not part of the final model & & -0.42 \\
Well-integrated $\times \ldots$ & -0.021 & -0.017 & -0.75 \\
$\quad \ldots \times$ IDG & -0.028 & \\
$\quad \ldots \times$ CMC & -0.040 &
\end{tabular}

not help to avoid a delay during a research project. The other results are not surprising. Researchers with more years of research experience are less likely to suffer from delays during a project.

Within the group of peripheral researchers there is another significant effect. Peripheral researchers who visit more conferences have a higher probability of experiencing such a delay. For well-integrated researchers the number of visited conferences has no significant effect.

As a result, there are no IDG-effects relating to practical, helpful information benefits, neither for well-integrated nor for peripheral researchers.

Table 6 presents the results of the analyses of weak contacts.

The model 'explains' $43 \%$ of the variance of the weak contacts. With the exception of the years of research experience, every variable shows a significant positive effect. Most interesting, the opportunities offered by IDGs have a significant positive effect $(P<0.01)$ of a moderate size (beta $=0.07$ ). The larger the opportunities offered by his or her IDGs are, the more visible is a researcher's work and the more he or she becomes aware of other researchers' work. This effect on a researcher's weak contacts clearly does not differ between peripheral and integrated researchers $(P=0.68)$. As a consequence, the data support the weak contact hypothesis, but not the peripherality hypothesis.

Moreover, better integrated researchers, more prominent researchers, researchers who communicate more often with their colleagues, who use CMC tools more often, who visit more conferences or write more papers have more weak contacts, which is what one would expect. None of these effects differs between peripheral or well-integrated researchers.

Table 7 shows the results for the reception contacts. Whereas the results of Table 6 showed that IDGs affect how visible a researcher is to his community and how much aware he is of 
Table 7

Reception contacts

\begin{tabular}{|c|c|c|}
\hline Variable & $B$ & Wald (d.f. = 1) \\
\hline \multicolumn{3}{|l|}{ Main effects } \\
\hline IDG & $0.196^{* *}$ & 7.52 \\
\hline $\mathrm{CMC}$ & 0.098 & 1.6 \\
\hline Communication frequency & 0.045 & 0.77 \\
\hline Prominence & 0.099 & 2.56 \\
\hline Research experience & -0.008 & 0.73 \\
\hline \#Conferences & 0.042 & 1.38 \\
\hline \#Papers & $0.079^{* *}$ & 7.58 \\
\hline Integration & $0.539^{* * *}$ & 16.58 \\
\hline \multicolumn{3}{|l|}{ Interaction effects } \\
\hline \multicolumn{3}{|l|}{ Well-integrated $\times \ldots$} \\
\hline \multirow[t]{2}{*}{$\ldots \times$ Prominence } & $-0.344^{* * *}$ & 21.66 \\
\hline & \multicolumn{2}{|c|}{ Model $\chi^{2}=54.79$, d.f. $=9, n=820, P=0.000$} \\
\hline \multirow{2}{*}{\multicolumn{3}{|c|}{$\begin{array}{l}\text { Additional non-significant interaction effects which are not part of the final model } \\
\text { Well-integrated } \times \ldots\end{array}$}} \\
\hline & & \\
\hline$\ldots \times$ IDG & 0.108 & 0.57 \\
\hline$\ldots \times \mathrm{CMC}$ & 0.117 & 0.61 \\
\hline
\end{tabular}

Constant not shown, interaction variables centered.

${ }^{*} P<0.05$.

** $P<0.01$.

*** $P<0.001$.

his colleagues' research, the findings presented in Table 7 analyze whether the use of IDGs also results in the reception of more papers and articles. ${ }^{18}$

The main IDG effect on reception contacts is positive, and does reach significance $(P<$ 0.01). ${ }^{19}$ The interaction effect is not significant $(P=0.45)$, which implies that the effect of the IDG communication does not differ significantly between peripheral and integrated researchers. There is a significant effect of IDG use on the creation of reception contacts, but there is no support for any form of the equality hypothesis. Neither the peripherality hypothesis nor the strong equality hypothesis find any evidence.

Moreover, those who write more research papers and those who are better integrated receive more requested papers. Prominence has a significantly smaller effect for integrated researchers than for peripheral researchers. It seems that among the integrated researchers those who are more prominent do not become more active to receive papers than the less

\footnotetext{
18 More precisely, they analyse whether the greater the opportunities offered by IDGs, the more likely it is that the researcher is among the upper $50 \%$ of those researchers within his discipline (and within his group of peripheral or integrated researchers) who receive a larger number of requested papers.

19 The presented effect size underestimates the actual effect size. At the end of the 1990s many researchers get access to papers via the world-wide-web without having to ask the author explicitly for the paper. IDG communication can attract the researcher's attention to a specific web site that contains useful papers. The statistical model, however, does not take such indirect effects into account. It cancels out such indirect effects because they are mediated by one of the control variables, namely CMC use.
} 
Table 8

Collaboration

\begin{tabular}{lcc}
\hline Variable & \multicolumn{1}{c}{$B$} & Wald (d.f. $=1)$ \\
\hline Main effects & & \\
$\quad$ IDG & $0.154^{\mathrm{a}}$ & 2.86 \\
CMC & $0.342^{* *}$ & 11.29 \\
Communication frequency & 0.099 & 1.88 \\
Prominence & $0.200^{* *}$ & 8.48 \\
Research experience & 0.010 & 0.73 \\
\#Conferences & $0.110^{\mathrm{a}}$ & 3.38 \\
\#Papers & -0.027 & 0.52 \\
Integration & -0.027 & 0.01 \\
Interaction effects & & \\
Well-integrated $\times \ldots$ & & \\
$\quad \ldots \times$ \#Conferences & $-0.136^{*}$ & 4.43 \\
$\quad \ldots \times$ Integration & $0.795^{*}$ & 4.24 \\
$\quad \ldots \times$ Communication frequency & $0.257^{*}$ & 5.82 \\
& Model $\chi^{2}=150.39$, d.f. $=18, n=822, P=0.00$
\end{tabular}

Additional non-significant interaction effects which are not part of the final model

Well-integrated $\times \ldots$
$\ldots \times$ IDG
0.123
0.39
$\ldots \times \mathrm{CMC}$
$-0.320$
2.4
Constant and dummy variables for the disciplines not shown, interaction variables centered.
${ }^{\text {a }} P<0.1$.
* $P<0.05$.
** $P<0.01$.
*** $P<0.001$.

prominent do. Their high degree of integration is sufficient to stay informed about the ongoing work of colleagues, which makes it superfluous to ask for more papers.

The results of the test of the fifth hypothesis relating to collaboration contacts are shown in Table 8. The main effect of the IDG index which indicates the quantity of monthly-received IDG-E-mails is positive; however, it does not clearly reach significance $(P=0.09) .{ }^{20}$ The interaction effect is positive and not significant. There is no clear evidence for the hypothesis that IDGs are used in such a way that they increase the probability of finding a partner for research collaborations. ${ }^{21}$ Moreover, the effect does not differ between peripheral and well-integrated researchers $(P=0.53)$. The peripherality hypothesis and the strong equality hypothesis are not supported by the data.

\footnotetext{
${ }^{20}$ This is the result of a two-sided test. A one-sided test thus leads to a marginally significant effect. Given that the sample size is not small, however, one should be cautious to draw substantial conclusions about collaboration effects from this finding.

21 When I analysed the number of collaborators a researchers has (or a discipline specific ranking variable based on this number) with a multiple linear regression model, the IDG index showed a significant positive effect. The dependent variable, however, had a heavily skewed distribution and the residual analysis indicated that outliers biased the estimation outcomes.
} 
Table 9

Natural vs. social sciences

\begin{tabular}{|c|c|c|c|c|c|c|c|c|}
\hline \multirow[t]{2}{*}{ Variable } & \multicolumn{3}{|c|}{ Research information benefits } & \multicolumn{3}{|c|}{ Weak contacts } & \multicolumn{2}{|c|}{ Reception contacts } \\
\hline & $B$ & Beta & $T$ & $B$ & Beta & $T$ & $B$ & Wald (d.f. $=1)$ \\
\hline \multicolumn{9}{|c|}{ Interaction effects } \\
\hline \multicolumn{9}{|c|}{ Natural sciences $\times \ldots$} \\
\hline$\ldots \times \mathrm{IDG}$ & $-0.122^{*}$ & -0.081 & -2.28 & 0.050 & 0.030 & 0.92 & -0.091 & 0.38 \\
\hline$\ldots \times \mathrm{CMC}$ & -0.070 & -0.060 & -1.24 & $-0.131^{*}$ & -0.101 & -2.25 & 0.08 & 0.29 \\
\hline
\end{tabular}

${ }^{+} P<0.1 ;{ }^{*} P<0.05 ;{ }^{* *} P<0.01 ;{ }^{* * *} P<0.001$. Only additional interaction effects shown.

Additionally, more prominent researchers and researchers who more often use CMC tools, more often work collaboratively. Among the group of well-integrated researchers the degree of integration and the frequency of communication are related more strongly to collaborative work than among the group of peripheral researchers.

Another interesting question is whether the information and contact benefits differ between the natural and social sciences. To answer this question, I analyze again the three models that had significant IDG effects, namely the research information benefits, weak contacts and reception contacts by including two interaction terms. These interaction terms test whether the effects of the IDG opportunities and the effects of the general use of CMC differ for researchers in the natural sciences compared to those in the social sciences and the humanities. Table 9 shows the results of these three analyses.

There is a significant interaction effect relating to the research information benefits, that is, how well informed researchers feel about aspects of their research field and community. Researchers in the natural sciences profit significantly less from the opportunities offered by IDGs with regard to research information benefits than researchers in the social sciences $(P=0.02)$. More precisely, research information benefits exist only for researchers in the social sciences. There are no differences of the contact effects of IDG communication between researchers in the natural and social sciences. For both regression analyses these two interaction effects are clearly non-significant $(P=0.36$ and $P=0.54)$. Researchers in the natural sciences, social sciences, and humanities do not differ in the way they profit from the use of IDGs with regard to their weak contacts and reception contacts.

\subsection{Summary and discussion of the results}

Fig. 2 presents a summary of the results.

The presented results show that IDG use has some beneficial information effects. There are effects relating to research information benefits, but none relating to practical, helpful information benefits. The effect sizes are the same for the groups of peripheral and integrated researchers. Thus, there are no equalizing effects, implying that IDGs do not provide more information benefits for peripheral researchers than for well-integrated researchers.

The results relating to the contact networks indicate that the researchers' use of active IDGs leads to more weak contacts. Active IDGs enhance the visibility of their work to other researchers and they become more aware of other researchers' papers, which they subsequently request. Moreover, this leads to a higher number of papers or articles 


\begin{tabular}{|c|c|}
\hline hypotheses about individual benefits & evidence \\
\hline research information benefits & yes \\
\hline practical helpful information benefits & no \\
\hline weak contact benefits & yes \\
\hline reception contact benefits & yes \\
\hline strong contact benefits & only weak evidence \\
\hline hypotheses about macro outcomes & evidence \\
\hline peripherality hypothesis & $\begin{array}{l}\text { no } \\
\text { (no differential effects between peripheral versus } \\
\text { well-integrated researchers) }\end{array}$ \\
\hline strong equality hypothesis & $\begin{array}{l}\text { no } \\
\text { (no differential effects between peripheral versus } \\
\text { well-integrated researchers for reception contacts } \\
\text { or strong contacts) }\end{array}$ \\
\hline
\end{tabular}

Fig. 2. Summary of the results.

received by the researcher, implying that IDGs lead to more reception contacts. However, the results do not clearly confirm the expectation that IDGs do lead to a regular extension of these researchers' networks. There is no convincing evidence that they generate new collaborations in substantial numbers.

This may be because there is only a minority of high quality IDGs that provide enough opportunities to create new collaborations. Another possibility is that E-Mail communication in general does not provide enough cues for the development of intensive contacts between researchers, as media richness theory states (Daft and Lengel, 1986). ${ }^{22}$ Further research is needed to clarify this question.

None of the contact effects differ between peripheral and integrated researchers. The opportunities offered by IDGs are beneficial for both groups of researchers in the same way, namely through increasing their weak and reception contacts. IDGs do not reduce the gap between the two groups of researchers with respect to these contacts.

This is at odds with any equality hypothesis (peripherality hypothesis, strong equality hypothesis) that predicts that IDGs reduce inequalities in the distribution of access opportunities (Gresham, 1994; Walsh and Bayma, 1996b). IDGs are useful for those who have less contacts, but not more so than for those with more contacts. The data does not support the hope that IDGs have an effect that counteracts the Matthew effect in science.

The three significant effects for research information benefits, weak contacts and reception contacts are results of the IDG use by the individual researcher, which means that they are individual-level effects. An alternative explanation is that they result from more frequent use of IDGs (or other CMC tools) in the whole university department. This implies that

\footnotetext{
${ }^{22}$ I would like to thank Emmanuel Koku (University of Toronto) for drawing my attention to this possibility.
} 
department members in general profit from these tools independently from their own frequency of use, meaning that the effects are compositional or group-level effects. Additional multilevel analyses (Matzat, 2001) made clear that this group-level interpretation is wrong.

There are no research findings that can easily explain why researchers in the natural sciences should profit less, or not at all, with regard to information benefits, as the results shown in Table 9 indicate. The following ideas are a tentative explanation of these findings. ${ }^{23}$

The research information effect is most of all due to the factor that users in more active IDGs feel better informed about ongoing conferences and about the names of the currently most active researchers. The informal communication system differs strongly between the natural sciences and the social sciences. Other studies have shown that physicists in particular can easily find out which other researchers are currently active in their research area. Their informal communication system efficiently helps them to stay informed, whereas researchers in the social sciences and humanities work much more in isolation and have more difficulties in getting an overview of their research area (Becher, 1989; Cole and Cole, 1968; Taubes, 1994). This might explain why above all researchers in the social sciences and humanities profit in this way from IDGs. It is a very basic orientation need that IDGs may fulfill in these research areas, but this need is already fulfilled to some degree by the informal communication system in the natural sciences. ${ }^{24}$

The results have important implications for the general relevance that IDGs can have for the structure of academic communication. The most general basic function that IDGs are expected to have is that they keep researchers informed. However, it not so much the information transfer within the IDG that is most important. The data indicates that researchers do not obtain advantageous practical, helpful information benefits through IDGs. It might be that this kind of information benefit is of more relevance for undergraduate students or non-university researchers, who were not included in the respondents of this study. Research information benefits, which consist of the kind of information that is directly related to the research field or the research community, are gained through IDGs. At the same time, they are restricted to researchers in the humanities and social sciences.

The data indicates that the creation of social contacts is a consequence of more general relevance than the transfer of information. These contacts consist of new weak contacts that enhance the researchers' visibility and awareness of colleagues' work, and contacts that help in receiving research papers. I draw the conclusion that IDGs are most of all useful for the creation of social contacts due to three reasons. Table 9 showed that the information effects are restricted to researchers in the social sciences and humanities. The contact effects, however, are relevant to researchers in the humanities, the social and the natural sciences. Second, the three contact hypotheses as a whole receive more support than the two information hypotheses of which one hypothesis clearly receives no support. Third, the confirmed information effects are more related to persons or social events (conferences) than to the theoretical content of the research field (see footnote 17).

\footnotetext{
23 The difference in the effect size for research information benefits does not depend on the proportion of IDG users in the researcher's department, as additional multilevel analyses made clear (not shown here). Moreover, the IDG effect sizes do not depend on the researcher's sex, country, or degree of CMC use (not shown here).

24 See Matzat (2002) for an elaboration of this idea to explain which characteristics of the communication system of a discipline stimulate the use of IDGs.
} 
To interpret this outcome in another way, the benefits that researchers obtain in the background of an IDG, that is, the enlargement of the 'private' networks, are of more general relevance than the benefits they gain through what happens 'in public' within the IDG, that is, the public transfer of information. Active IDGs can serve as a gateway to new informal networks that are not necessarily stabilized, but nevertheless provide helpful contacts. Understood in this way, they provide a form of social capital (Lin, 1999).

\section{General summary and conclusions}

This paper reviewed some hypotheses relating to the consequences of IDGs for the structure of academic communication. Several hypotheses with regard to potential information and contact benefits of IDGs were tested. The results show that almost one in four of all English or Dutch university researcher used at least one IDG. Only a very small minority of researchers uses newsgroups, whereas academic mailing lists are much more popular in every discipline.

There is support for hypotheses about information effects and, more often, contact benefits that are valuable for peripheral and integrated researchers. In particular, researchers in the social sciences and humanities profit from the use of mailing lists through attaining some research information benefits, which implies that they feel better informed about different aspects of their research field and research community. Moreover, the research work of scholars in the social sciences, the humanities, and the natural sciences becomes more visible to others in their field and researchers become more aware of their colleagues' output. Researchers succeed in building up links that help in receiving more published articles or unpublished papers. At the same time there is no clear evidence that these effects of IDGs lead to changes in the long-term collaboration networks of researchers. In this sense, IDGs may be regarded as a kind of unstable social capital. By and large, there is more evidence for the attainment of contact benefits than there is for the attainment of information benefits.

Contrary to what is expected in the literature (Gresham, 1994; Hiltz and Turoff, 1978; Hesse et al., 1993; Walsh and Bayma, 1996b; Walsh, 1998), there are no equalizing effects of IDGs in the sense that those who have less profit more. IDGs do not reduce inequalities in the opportunities to access informal communication channels. The results indicate that it is reasonable to assume that researchers at the bottom of the status hierarchy will have more opportunities to participate through the use of IDGs than they had in the past, as some analysts argue (e.g. Walsh and Bayma, 1996b). One may be inclined to argue that this is of more importance for peripheral than integrated researchers. Nevertheless, the results showed that this does not imply a reduction of inequality to any substantial degree.

Since such a large-scale study hardly could avoid the use of self-reported questionnaire data, it would be useful to try to replicate the findings in another study that (a) makes use of electronic log-file data about Internet use and that (b) measures changes of the researchers' contact networks in a longitudinal study. Such a replication would be less subject to the objection that the data might be influenced by measurement errors that are often to find in self-reported data (Schwarz, 1999). The reader should take into account that the presently 
available evidence for benefits of IDG use makes use of self-reports. Evidence that is based on more objective measurements is not yet available.

It may be asked what wider implications these results have for academic communication and for the analysis of social networks? First of all, the results support the point of view that academic mailing lists are an important tool for the academic communication system. To a certain degree, they extend the researchers' communication network. For some subgroups, they provide useful information about the research community. Although newer possibilities provided by the Internet for online-publishing attract more attention (e.g. Peek and Newby, 1996), these traditional tools of electronic communication must not be underestimated in their relevance. There is evidence for some beneficial effects.

Second, IDGs can fulfill some communication needs, particularly in the social sciences and the humanities. At the same time, one has to realize that these effects are only of moderate size. Although IDGs can be remedies for specific problems (e.g. for getting an overview of some research areas), they should not be overloaded with hopes for the coming technological utopia. They do not fulfill far-reaching expectations. They just are useful tools for certain specific purposes.

Third, the results should also draw more attention of social network researchers to the theoretical and empirical analysis of CMC tools and the Internet. There are numerous predictions about the consequences of the Internet for the emergence of a "global village" (Matzat, 2000). Empirical evidence for these hopes (or fears) is missing. Social network researchers, in particular, could show through the detailed study of different kinds of new ties which may emerge through the use of the Internet, whether this term is justified and what it really means. This paper shows that it is justified to speak of the provision of social capital through electronic groups. But which factors stimulate this provision? Most of all, theory is needed to tell us under which conditions different kinds of links emerge and which conditions make electronic groups an efficient tool for the transfer of information.

For example, it is unclear whether mailing lists help to form stable links between researchers. On the one hand, this might be due to the restricted possibilities that E-Mail communication in general offers for collaboration. On the other hand, there seem to be differences in the usefulness of mailing lists. The fact that a number of lists were evaluated as having no relevance for the respondent's most important research field suggests that there are differences in the quality of mailing lists. Moreover, the analysis has shown that the usefulness of an IDG clearly depends on differences in the degree of communication within it. Active mailing lists provide more opportunities for the formation of ties than mailing lists with only a few messages. It is not enough to ask whether electronic groups provide social capital, but also when. It is important to study under which conditions mailing lists are better suited to provide opportunities for the creation of new ties and information benefits. Which properties do useful mailing lists have and why are these properties important? What kinds of researchers are active participants in mailing lists? Are the most experienced researchers the main information providers? What determines the extent to which help and information is provided in electronic groups and thereby the group's usefulness? Do off-line social networks influence online-communication (Wellman, 1999)? If yes, then how?

An important conclusion of this paper is that even in academic electronic groups 'social' benefits matter more than information benefits. Such an insight is useful not only for academic electronic groups. Social incentives could be used to stimulate electronic interaction 
in general, if active participation in an electronic group could be a means of obtaining these benefits. Further research has to clarify whether the goal of making new contacts drives active participation in electronic groups. Such knowledge about behavioral mechanisms which steer electronic interaction is crucial for designing and managing electronic groups such as online-communities through the creation of the right incentive system to stimulate interaction. Much more theoretically guided research on the interaction in electronic groups is needed to solve this task.

\section{Acknowledgements}

I am very thankful to Tom Snijders (ICS Groningen) for support and helpful comments on earlier drafts of this paper. Parts of this paper profited from discussions and presentations at the XXth Sunbelt Social Network Conference, Vancouver, Canada (April 13-16, 2000), at the 95th Annual Meeting of the American Sociological Association, Washington DC, USA (12-16 August, 2000), at the 6th meeting of the German Section of the International Society for Knowledge Organization, Hamburg, Germany (23-25 September, 1999), from discussions with B. Wellman and B. Erickson during a research stay at the Center for Urban and Community Studies (University of Toronto, Canada), and from comments of two anonymous reviewers. I gratefully acknowledge subsidies from the Dutch Science Foundation (NWO-Grants SIR 12-3827 and SIR 12-3946). 


\section{Appendix: The measurement of the variables}

\begin{tabular}{|c|c|c|}
\hline dependent variable & & item(s) / measurement \\
\hline \multirow[t]{2}{*}{$\begin{array}{l}\text { research information } \\
\text { benefits }\end{array}$} & \multicolumn{2}{|c|}{$\begin{array}{l}\text { Some researchers within a research field may be better informed about current developments within the } \\
\text { field than other researchers of that field - depending on their research experience, contacts and other } \\
\text { things. } \\
\text { How well informed do you feel about different aspects of your research field? (Circle the number that } \\
\text { applies best for you.) How well informed do you feel about.... } \\
\text { a)... the most important literature? } \\
\text { b)... the names of the currently most active researchers? } \\
\text { c)...the newest "progress of the research front" (e.g. not yet officially published findings, not yet solved } \\
\text { research problems etc.)? } \\
\text { d)...conferences that are actually taking place? }\end{array}$} \\
\hline & \multicolumn{2}{|c|}{$\begin{array}{l}\text { The four variables (answers on seven-point Likert scales with scores from "1" to "7") were } \\
\text { standardized for every discipline and then summarized by way of a principal component analysis that } \\
\text { resulted in one principal component with an eigenvalue larger than one. The component summarizes } \\
63,84 \% \text { of the variance of the items (KMO-measure of sampling adequacy=.78, all loadings }>=+.73 \text {, } \\
\text { standardized } \alpha \text { of the four items }=.81 \text { ) }\end{array}$} \\
\hline \multirow[t]{5}{*}{$\begin{array}{l}\text { practical information } \\
\text { benefits } \\
\text { ( } 2 \text { variables) }\end{array}$} & \multicolumn{2}{|c|}{$\begin{array}{l}\text { a) ease of access to the helping knowledge of colleagues: self-rating on a seven-point Likert scale: } \\
\text { Most researchers have sometimes minor, special problems or questions that they cannot answer on their } \\
\text { own, but that are nevertheless important for the continuity of the research, so that they have to contact } \\
\text { other expert colleagues for assistance. Such problems can include software difficulties, literature } \\
\text { retrieval problems, special technical problems and many more. When you think of the last time you had } \\
\text { such a problem, how difficult or easy was it for you in this situation to get help/answers from expert } \\
\text { colleagues? }\end{array}$} \\
\hline & \multirow{2}{*}{\multicolumn{2}{|c|}{$\begin{array}{l}\text { (answers of respondents who chose the option 'I did not have such a problem during the last } 12 \text { months' } \\
\text { were excluded) } \\
\text { b) delay (questions asked immediately after the last question) }\end{array}$}} \\
\hline & & \\
\hline & $\begin{array}{l}\text { Did it happen during the last } 12 \\
\text { months that such a "minor, special } \\
\text { problem" delayed your research, } \\
\text { because it took too much time or } \\
\text { energy to find the help you } \\
\text { needed? }\end{array}$ & $\begin{array}{l}\text { In some research fields it is easily possible that a researcher gets } \\
\text { an important published or unpublished paper or an important } \\
\text { article too late (or hears of its existence too late), so that his/her } \\
\text { own research gets delayed and/or a research paper must be } \\
\text { rewritten. } \\
\text { How often did this happen to you during the last } 12 \text { months? }\end{array}$ \\
\hline & \multicolumn{2}{|c|}{$\begin{array}{l}\text { The answer to the second question was dichotomized and the final variable "delay" has the value one if } \\
\text { at least one of the two events did happen during the last } 12 \text { months. }\end{array}$} \\
\hline weak contacts & \multicolumn{2}{|c|}{$\begin{array}{l}\text { a) How often during the last } 12 \text { months were you personally asked by other researchers (at a meeting, } \\
\text { per mail, fax, E-Mail etc.) for manuscripts, publications, articles, or pre-prints of publications? } \\
\text { b) How often during the last } 12 \text { months did you personally ask other researchers (at a meeting, per } \\
\text { mail, fax, E-Mail etc.) for manuscripts, publications, articles, or pre-prints of publications? } \\
\text { c) With how many researchers in your research field (excluding researchers at your own department) do } \\
\text { you have "contact"? With a "contact" we mean that either you approached the researcher (for } \\
\text { questions, sending papers etc.) at least } 2 \text { times or he approached you at least } 2 \text { times on different } \\
\text { occasions during the last } 12 \text { months. Such contacts include all communication modes (face-to-face } \\
\text { meetings, mails, E-Mails, faxes etc.) that lead to an information transfer of professional use for you. } \\
\text { I took the natural logarithm of these numbers (plus one) and summarized them by way of a principal } \\
\text { component analysis which resulted in one component with an eigenvalue larger than one. The } \\
\text { component summarizes } 69,74 \% \text { of the variance of the items (KMO-measure of sampling } \\
\text { adequacy=.67, all loadings }>=+.77 \text {, standardized } \alpha \text { of the three items=.78) }\end{array}$} \\
\hline \multirow[t]{4}{*}{ reception contacts } & \multicolumn{2}{|c|}{$\begin{array}{l}\text { First I asked the respondents two questions relating to the number of unpublished papers and published } \\
\text { articles that they received during the last } 12 \text { months. }\end{array}$} \\
\hline & \multicolumn{2}{|c|}{$\begin{array}{l}\text { What is the total number of published articles that were sent to you during the last } 12 \text { months by } \\
\text { other researchers? Include in this calculation all the articles you got, whether you have asked for } \\
\text { them or not. } \\
\text { What is the total number of manuscripts (excluding manuscripts reviewed for a journal), unpublished } \\
\text { papers, and pre-prints of publications that were sent to you during the last } 12 \text { months by other } \\
\text { researchers? Include in this calculation all the papers you got, whether you have asked for them or } \\
\text { not. }\end{array}$} \\
\hline & \multicolumn{2}{|c|}{$\begin{array}{l}\text { From these two numbers I subtracted those articles and unpublished papers that the respondent did not } \\
\text { ask for. }\end{array}$} \\
\hline & \multicolumn{2}{|c|}{$\begin{array}{l}\text { How often does it happen that you get sent published articles of other researchers although you did } \\
\text { not ask for that? Try to estimate the number of articles that were sent to you during the last } 12 \\
\text { months by other researchers although you did not ask for them! } \\
\text { How often does it happen that you get sent pre-prints of publications or manuscripts of other } \\
\text { researchers although you did not ask for that? Try to estimate the number of pre-prints of } \\
\text { publications, unpublished papers or manuscripts that were sent to you during the last } 12 \text { months by } \\
\text { other researchers although you did not ask for them. Exclude in the estimation all reviewed } \\
\text { manuscripts! }\end{array}$} \\
\hline
\end{tabular}




\begin{tabular}{|l|l|}
\hline & $\begin{array}{l}\text { This results in two scores that were separately ranked for every discipline. The mean of the two } \\
\text { discipline-specific rankings was dichotomized separately for the group of peripheral researchers and } \\
\text { the group of well-integrated researchers with the group specific median as the cut-point. The } \\
\text { dichotomization was done to avoid a skewed distribution of the dependent variable caused by the high } \\
\text { number of researchers who didn't get many manuscripts or articles. }\end{array}$ \\
\hline strong contact & $\begin{array}{l}\text { The variable (collaboration) scores one when the respondent answers that he has at least one of the } \\
\text { following two types of collaboration }\end{array}$ \\
\cline { 2 - 2 } & $\begin{array}{l}\text { With how many researchers in your research field did you collaborate during the last } 12 \text { months? With } \\
\text { a collaborator we mean another researcher who is responsible for one or more of the main elements } \\
\text { of one of your projects or with whom you worked together for a large part of it. Exclude researchers } \\
\text { at your own department and all research students!" } \\
\text { "With how many research students did you collaborate in your research field during the last } 12 \\
\text { months? Exclude research students at your own department and those that you supervise! }\end{array}$ \\
\hline
\end{tabular}

\begin{tabular}{|l|l|}
\hline \multicolumn{1}{|c|}{ independent variable } & \multicolumn{1}{c|}{ measurement } \\
\hline $\begin{array}{l}\text { Index of the } \\
\text { opportunities offered by } \\
\text { IDGs }\end{array}$ & $\begin{array}{l}\text { I selected only those mailing lists or newsgroups in which the respondent was subscribed for at } \\
\text { least } 2 \text { months (or which he used regularly for at least } 2 \text { months in the case of newsgroups). } \\
\text { Furthermore, I selected only those IDGs which the respondent evaluated as having a "direct or } \\
\text { indirect relevance for the research field" in which he is most actively doing research. This ensures } \\
\text { that I choose only those IDGs that the researcher is acquainted with, that have a research } \\
\text { orientation and that have a minimum quality. For every respondent I added up the estimated } \\
\text { number of monthly messages sent to all selected IDGs. I did this separately for mailing lists and } \\
\text { newsgroups. These total numbers of monthly messages were coded into five categories. (For the 12 } \\
\text { respondents who used mailing lists and newsgroups I took the maximum number of these two } \\
\text { variables as the final index.) This variable constitutes the IDG index. }\end{array}$ \\
\hline $\begin{array}{l}\text { The assumption, which is tested empirically, is that the higher the average number of messages, the more opportunities there are } \\
\text { for getting in contact with other researchers or for obtaining information benefits. The coding into five categories takes into } \\
\text { account that there are some upper limits for this number after which additional messages hardly have any additional effect on the } \\
\text { created opportunities for the receiver. Moreover, this operationalization of the opportunities makes possible only one plausible } \\
\text { interpretation of what might be the "cause" and what might be the "effect". The average number of monthly messages sent to } \\
\text { different IDGs cannot be determined by e.g. how well informed the researcher feels about different aspects of his/her research } \\
\text { field. }\end{array}$ & \multicolumn{2}{|l}{}
\end{tabular}

\begin{tabular}{|c|c|}
\hline control variables & items / measurement \\
\hline $\begin{array}{l}\text { general frequency of } \\
\text { communication }\end{array}$ & $\begin{array}{l}\text { How frequently do you generally communicate with other researchers regarding your own } \\
\text { research? answer categories: } 1 \text { rarely } 2 \text { monthly } 3 \text { biweekly } 4 \text { weekly } 5 \text { almost daily } \\
6 \text { daily }\end{array}$ \\
\hline prominence & $\begin{array}{l}\text { How well known is your work within your most important field of research? (seven point Likert } \\
\text { scale) }\end{array}$ \\
\hline $\begin{array}{l}\text { years of research } \\
\text { experience }\end{array}$ & How long have you been actively working within your research field? \\
\hline conference participation & How often did you attend conferences and official scientific meetings during the last 12 months? \\
\hline written research output & $\begin{array}{l}\text { How many research papers did you write (published and unpublished papers including those } \\
\text { articles already mentioned) during the last } 12 \text { months? }\end{array}$ \\
\hline \multirow[t]{2}{*}{ use of CMC tools } & $\begin{array}{l}\text { On how many days per week do you -on average- use a computer/communicate by E-Mail/read a } \\
\text { 'World-Wide-Web-page'/ use the 'file transfer protocol' (ftp) to copy data from other computer for } \\
\text { professional reasons? }\end{array}$ \\
\hline & $\begin{array}{l}\text { The answers to these four separately asked questions were scaled on a Likert scale from zero to } \\
\text { seven (with half days as the unit of measurement). A principal component analysis of the } \\
\text { standardized variables resulted in one principal component with an eigenvalue larger than one. The } \\
\text { component summarizes } 56.4 \% \text { of the variance of the items (KMO-measure of sampling } \\
\text { adequacy }=.70 \text {, all loadings }>=+.65 \text {, standardized } \alpha \text { of the four items }=.74 \text { ) }\end{array}$ \\
\hline \multirow[t]{5}{*}{ Integration/peripherality } & $\begin{array}{l}\text { How often does it happen that you get sent published articles of other researchers although you } \\
\text { did not ask for that? Try to estimate the number of articles that were sent to you during the last } 12 \\
\text { months by other researchers although you did not ask for them! }\end{array}$ \\
\hline & $\begin{array}{l}\text { How often does it happen that you get sent pre-prints of publications or manuscripts of other } \\
\text { researchers although you did not ask for that? Try to estimate the number of pre-prints of } \\
\text { publications, unpublished papers or manuscripts that were sent to you during the last } 12 \text { months by } \\
\text { other researchers although you did not ask for them. Exclude in the estimation all reviewed } \\
\text { manuscripts }\end{array}$ \\
\hline & How many manuscripts did you review as a journal reviewer during the last 12 months? \\
\hline & $\begin{array}{l}\text { When you have written a research paper, to how many other researchers do you -on average- send a } \\
\text { pre-print of publication or the manuscript? }\end{array}$ \\
\hline & $\begin{array}{l}\text { The answers to these four questions were separately ranked for every discipline. A principal } \\
\text { component analysis on these four ranking variables resulted in one principal component with an } \\
\text { eigenvalue larger than one which was taken as the measurement for the degree of integration. The } \\
\text { component summarizes } 55.1 \% \text { of the variance of the items (KMO-measure of sampling } \\
\text { adequacy }=.69 \text {; all loadings }>=+.56 \text {, standardized } \alpha \text { of the four items }=.72 \text { ) }\end{array}$ \\
\hline
\end{tabular}




\section{References}

Bainbridge, William S., 1995. Sociology on the World-Wide-Web. Social Science Computer Review 4, $508-523$. Becher, T., 1989. Academic Tribes and Territories. Intellectual Enquiry and the Cultures of the Disciplines. The Society for Research into Higher Education \& Open University Press.

Berge, Z.L., Collins, M., 1993. The Founding and Managing of IPCT-L: A Listowners' Perspective. Interpersonal Computing and Technology(2) Retrieved 11-20-2000 from the World Wide Web: http://www.emoderators.com/ipct-j/1993/n2/berge.txt.

Cairncross, F., 1997. The Death of Distance: How the Communication Revolution Will Change Our Lives. Business School Press, Boston MA.

Carley, Kathleen, Wendt, Kira., 1991. Electronic mail and scientific communication. Knowledge: Creation, Diffusion, Utilization 4, 406-440.

Cohen, Joel., 1996. Computer mediated communication and publication productivity among faculty. Internet Research 2/3, 41-63.

Cole, Stephen, Cole, Jonathan R., 1968. Visibility and the structural bases of awareness of scientific research. American Sociological Review 33, 397-413.

Conner, Patrick W., 1992. Networking in the humanities: lessons Form ANSAXNET. Computers and the Humanities 26, 195-204.

Crane, Diane., 1969. Social structure in a group of scientists: a test of the "invisible college" hypothesis. American Sociological Review 34, 335-352.

Crane, D., 1972. Invisible Colleges. Diffusion of Knowledge in Scientific Communities. The University of Chicago Press, Chicago.

Cronin, Blaise., 1982. Progress in documentation: invisible colleges and information transfer. Journal of Documentation 3, 212-236.

Daft, Richard L., Lengel, Robert H., 1986. Organizational information requirements, media richness, and structural design. Management Science 5, 554-571.

Deane, Frank P., John, Podd, Ron, D. Henderson., 1998. Relationship between self-report and log data estimates of information system usage. Computers in Human Behavior 14 (4), 621-636.

Freeman, Linton C., 1984. The impact of computer based communication on the social structure of an emerging scientific specialty. Social Networks 6, 201-221.

Garvey, W.D., 1979. Communication: The Essence of Science. Pergamon Press, Oxford, New York, Toronto, Sydney, Paris, Frankfurt.

Garvey, William D., Griffith, Belver C., 1966. Studies of social innovations in scientific communication in psychology. American Psychologist 21, 1019-1036.

Gaston, J., 1972. Communication and the reward system of science: a study of a national invisible college. In: Halmos, P., Albrow., M. (Eds.), The Sociology of Science. J.H. Bookes Limited, pp. 25-41.

Gresham Jr., John L., 1994. From invisible college to cyberspace college: computer conferencing and the transformation of informal scholarly communication networks. Interpersonal Computing and Technology: An Electronic Journal for the 21st Century 4, 37-52.

H-Net Webstaff, 1999. What is H-Net? Retrieved 7-11-1999 from the World Wide Web: http://www.h-net.msu.edu/about/.

Hagstrom, W.O., 1965. The Scientific Community. Basic Books, New York.

Harasim, Linda M., Winkelmans, Tim., 1990. Computer-mediated collaboration. A case study of an international online educational workshop. Knowledge: Creation, Diffusion, Utilization 4, 382-409.

Haythornwaite, Caroline, Wellman, Barry., 1998. Work, friendship and media use for information exchange in a networked organization. Journal of the American Society for Information Science 12, 1101-1114.

Hesse, Bradford W., Sproull, Lee S., Kiesler, Sara B., Walsh, Jon P., 1993. Returns to science: computer networks in oceanography. Communications of the Association of Computing Machinery (ACM) 8, 90-101.

Hicks, Daniel M., Katz, J. Sylvan., 1996. Where is science going? Science, Technology \& Human Values 4, 379-406.

Hiltz, S.R., 1984. Online Communities. A Case Study of the Office of the Future. Publishing Corporation, Norwood, New Jersey.

Hiltz, S.R., Turoff, M., 1978. The Network Nation: Human Communication via Computer. The MIT Press, Cambridge, Massachusetts and London, UK. 
Katz, J. Sylvan, Martin, R. Ben., 1997. What is research collaboration? Research Policy 26, 1-18.

Kling, Rob., 1996. Synergies and competition between life in cyberspace and face-to-face communities. Social Science Computer Review 1, 50-54.

Kling, R., Iacono, S., 1995. Computerization movements and the mobilization of support for computerization. In: Star, S.L. (Ed.), Ecologies of Knowledge. Albany, pp. 119-153.

Kling, Rob, McKim, Geoffrey., 2000. Not just a matter of time: field differences and the shaping of electronic media in supporting scientific communication. Journal of the American Society for Information Science 14, 1306-1320.

Koku, Emmanuel, Nancy, Nazer, Barry, Wellman., 2001. Netting scholars: online and offline. American Behavioral Scientist 10, 1750-1772.

Korenman, J., Wyatt, N., 1996. Group Dynamics in an E-Mail Forum. In: Herring, S.C. (Ed.), Computer-mediated Communication. Linguistic, Social and Cross-Cultural Perspectives. Amsterdam, Philadelphia, pp. $225-242$.

Kovacs, D.K., 1996. 11th Revision Directory of Scholarly and Professional E-Conferences. Retrieved 11-20-1996 from the World Wide Web: http://www.n2h2.com/kovacs/whatis.html.

Kraut, R.E., Egido, C., Gelegher, J., 1990. Patterns of contact and communication in scientific research collaboration. In: Gelegher, J., Kraut, R.E., Egido, C. (Eds.), Intellectual Teamwork. Social and Technological Foundations of Cooperative Work. Hillsdale, New Jersey, Hove and London, pp. 149-171.

Kraut, Robert E., Gelegher, Jolene, Egido, Carmen., 1987. Relationships and tasks in scientific research collaboration. Human-Computer Interaction 3, 31-58.

Lewenstein, Bruce V., 1995. Do public electronic bulletin boards help create scientific knowledge? The cold fusion case. Science, Technology \& Human Values 2, 123-149.

Lievrouw, L.A., 1990. In: Borgman, C.L. (Ed.), Reconciling Structure and Process in the Study of Scholarly Communication. Sage Publications, pp. 59-69.

Lin, Nan., 1999. Building a network theory of social capital. Connections 1, 28-51.

Lubanski, A., Matthew, L., 1998. Socio-economic Impact of the Internet in the Academic Research Environment. Retrieved 10-23-1998 from the World Wide Web: http://www.sosig.ac.uk/iriss/papers/paper18.html.

Luukkonen, Terttu, Persson, O., Silvertsen, G., 1992. Understanding patterns of international scientific collaboration. Science, Technology and Human Values 1, 101-126.

Mailbase, 1999. Mailbase: An overview. Retrieved 9-4-1999 from the World Wide Web: http://www.mailbase.ac.uk/docs/overview.html.

Mailbase, 1999a. The Mailbase Service: More than just Mailing Lists. Retrieved 9-4-1999 from the World Wide Web: http://www.mailbase.ac.uk/lists.htm.

Mailbase, 1999b. Growth in the number of members (June '93 - January '99). Retrieved 8-18-1999 from the World Wide Web: http://www.mailbase.ac.uk/stats/members-growth.html.

Matzat, U., 2000. Academic communication and internet discussion groups: what kinds of benefits for whom? In: Batinic, B., Reips, U.D., Bosnjak, M. (Eds.), Online-Social Sciences. Hogrefe \& Huber Publishers, pp. $397-416$.

Matzat, U., 2001. Social Networks and Cooperation in Electronic Communities: A Theoretical-Empirical Analysis of Academic Communication and Internet Discussion Groups. Thela Publishers, Amsterdam.

Matzat, U., 2002. Disciplinary Differences in the Use of Internet Discussion Groups: Differential Communication Needs or trust Problems? (under review).

McCarty, Willard., 1992. Humanist: lessons from a global electronic seminar. Computers and the Humanities 26, 205-222.

Meadows, A.J., 1974. Communication in science. Butterworths, London.

Meadows, Anthony J., Buckle, P., 1992. Changing communication activities in the British scientific community. Journal of Documentation 3, 276-290.

Menzel, H., 1962. Planned and unplanned scientific communication. In: Barbe, B., Hirsch, W. (Eds.), The Sociology of Science. Free Press of Glancoe, New York, pp. 417-441.

Menzel, Herbert., 1966. Scientific communication: five themes from social science research. American Psychologist 21, 999-1004.

Merton, R.K., 1973. The Matthew effect in science. In: Merton, R.K. (Ed.), The Sociology of Science. Theoretical and Empirical Investigations. The University of Chicago Press, Chicago.

Pascha, L., 1995. Japan Im Netz. Eine Materialsammlung Zur Nutzung Des Internet. Center for East-Asian Studies (Institut fuer Ostasienwissenschaften), Duisburg, Germany. 
Peek, R.P., Newby, G.B., 1996. Scholarly Publishing. The Electronic Frontier. MIT Press, Cambridge, London.

Portes, Alejandro., 1998. Social capital: its origins and applications in modern sociology. Annual Revue of Sociology 22, 1-34.

Price, D.J. de S., 1963. Little Science, Big Science. Columbia University Press, New York.

Price, Derek J. de S., 1971. Some remarks on elitism in information and the invisible college phenomenon in science. Journal of the American Society for Information Science 22, 74-75.

Price, Derek J. de S., Beaver, D., 1966. Collaboration in an invisible college. American Psychologist 21, 10111018.

Rice, Ron P., 1997. An analysis of stylistic variables in electronic mail. Journal of Management and Technical Communication 1, 5-23.

Rojo, Alejandra, Ragsdale, R.G., 1997a. A process perspective on participation in scholarly electronic forums. Science Communication 4, 320-341.

Rojo, Alejandra, Ragsdale, R.G., 1997b. Participation in electronic forums: implications for the design and implementation of collaborative distributed multimedia. Telematics and Informatics 1, 83-96.

Rooy, F.J. van, 1996. Elektronische Discussielijjsten: Een Case-Studie. Retrieved 12-14-1996 from the World Wide Web: http://www.ubu.nl/EBU/a2-4.html.

Scholl, W., Pelz, J., Rade, J., 1997. Computervermittelte Kommunikation in Der Deutschen Wissenschaft. In: Batinic, B. (Ed.), Internet fuer Psychologen, Göttingen, Bern, Toronto, pp. 337-358.

Scholl, W., Pelz, J., Rade, J., 1996. Computervermittelte Kommunikation in Der Wissenschaft. Waxmann, Münster, New York, München, Berlin.

Schwarz, N., 1999. Self-reports-how the questions shape the answers. American Psychologist 54 (2), 93-105.

Taubes, Gary., 1994. Peer review in cyberspace. Science 266, 967.

Tombaugh, Jo W., 1984. Evaluation of an international scientific computer-based conference. Journal of Social Issues 3, 129-144.

Traore, Naomi, Landry, R., 1997. On the determinants of scientists' collaboration. Science Communication 2, 124-140.

Turoff, Murray, Hiltz, Star R., 1998. Superconnectivity. Communications of the Association of Computing Machinery (ACM) 7, 116.

Walsh, John P., 1998. Scientific communication and scientific work: a survey of four disciplines. Internet Research 4, 363-366.

Walsh, John P., Bayma, Todd., 1996a. Computer networks and scientific work. Social Studies of Science 26, 661-703.

Walsh, John P., Bayma, Todd., 1996b. The virtual college: computer-mediated communication and scientific work. The Information Society 12, 343-363.

Walther, Joseph B., 1995. Relational aspects of computer-mediated communication: experimental observations over time. Organization Science 2, 186-203.

Weedman, Judith., 1993. On the "isolation" of humanists. a report of an invisible college. Communication Research 6, 749-776.

Weil, Vivian., 1998. The information revolution. A dose of reality. Science Communication 1, 136-141.

Wellman, B., 1999. Net surfers don't ride alone: virtual communities as communities. In: Wellman, B. (Ed.), Networks in the Global Village, Westview Press, Boulder, CO, pp. 331-367.

Whitley, R., 1984. The Intellectual and Social Organisation of the Sciences. Clarendon Press, Oxford.

Whittaker, S., Sidner, C., 1997. E-mail overload: exploring personal information management of E-mail. In: Kiesler, S.B. (Ed.), Culture of the Internet. New Jersey, pp. 277-295.

Zaltman, G., 1974. A note on an international invisible college for information exchange. Journal of the American Society for Information Science 113-117.

Ziesemer, A., 1996. Verändert die Nutzung des Internet die Kommunikationsräume von Wissenschaftlern? Unpublished manuscript, Gerhard-Mercator-University Duisburg, Germany.

Ziman, J., 1994. Prometheus Bound. Science in a Dynamic Steady State. Cambridge University Press, Cambridge. 